San Jose State University

SJSU ScholarWorks

Master's Theses

Master's Theses and Graduate Research

Summer 2014

\title{
Examination of Multiparticle Transport as a Function of Slope and Sediment Volume
}

Alan Kuoch
San Jose State University

Follow this and additional works at: https://scholarworks.sjsu.edu/etd_theses

\section{Recommended Citation}

Kuoch, Alan, "Examination of Multiparticle Transport as a Function of Slope and Sediment Volume" (2014). Master's Theses. 4472.

DOI: https://doi.org/10.31979/etd.qfwj-e94e

https://scholarworks.sjsu.edu/etd_theses/4472

This Thesis is brought to you for free and open access by the Master's Theses and Graduate Research at SJSU ScholarWorks. It has been accepted for inclusion in Master's Theses by an authorized administrator of SJSU ScholarWorks. For more information, please contact scholarworks@sjsu.edu. 


\title{
EXAMINATION OF MULTIPARTICLE TRANSPORT AS A FUNCTION OF SLOPE AND SEDIMENT VOLUME
}

\author{
A Thesis \\ Presented to \\ The Faculty of the Department of Geology \\ San José State University \\ In Partial Fulfillment \\ of the Requirements for the Degree \\ Master of Science
}

by

Alan Kuoch

August 2014 
(C) 1993

Alan Kuoch

ALL RIGHTS RESERVED 
The Designated Thesis Committee Approves the Thesis Titled

EXAMINATION OF MULTIPARTICLE TRANSPORT AS A FUNCTION OF SLOPE

AND SEDIMENT VOLUME

by

Alan Kuoch

APPROVED FOR THE DEPARTMENT OF GEOLOGY

SAN JOSÉ STATE UNIVERSITY

August 2014

Dr. Emmanuel Gabet

Department of Geology

Dr. Robert Miller

Department of Geology

Dr. Dave Andersen

Department of Geology 


\begin{abstract}
EXAMINATION OF MULTIPARTICLE TRANSPORT AS A FUNCTION OF SLOPE AND SEDIMENT VOLUME

by Alan Kuoch
\end{abstract}

Recent studies of sediment transport have shifted from the traditional continuum paradigm to a particle-based approach. A previous dry ravel flume experiment on single particle transport showed that the angle of repose represented a shift between frictioncontrolled gentle slopes dominated by local transport and inertia-driven steep slopes dominated by nonlocal transport. My flume study explored multiparticle transport and the effect of sediment volume on transport distance. The flume experiments revealed a negative relationship between sediment volume and transport distance. As sediment volume increased, inter-particle collisions increased, which led to particle jamming and a reduction in transport distance. Furthermore, a higher transition slope was required for transport to shift into the inertial regime as a result of greater sediment volume. 


\section{ACKNOWLEDGEMENTS}

This thesis would not have been possible without the contributions of several people. First of all, I thank my parents, family, and friends for all of their love and support. Next, I thank my advisor, Dr. Emmanuel Gabet, for the endless discussions, countless e-mails, and guidance throughout this whole project. I also thank Dr. Dave Andersen and Dr. Robert Miller for their comments, discussion, and enthusiasm for this project. I also thank Alphonse Odisho for his kindness and contributions to the design and development of the dry ravel flume. Once again, I extend my deepest gratitude for all of their contributions to this project. 


\section{TABLE OF CONTENTS}

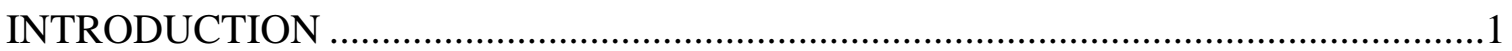

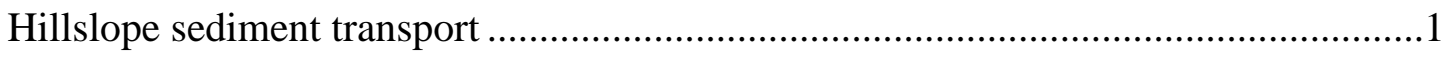

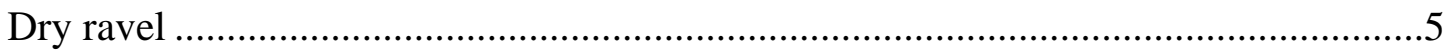

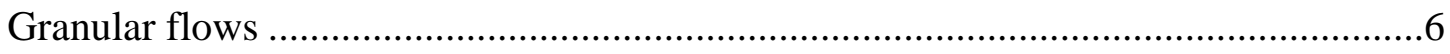

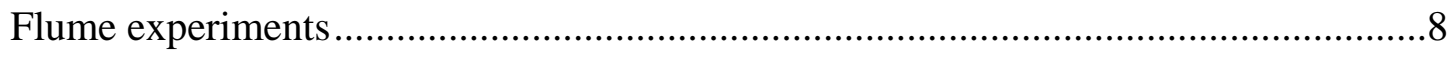

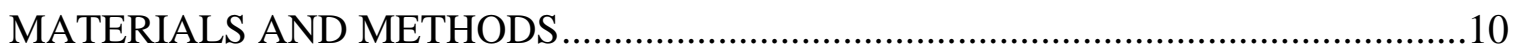

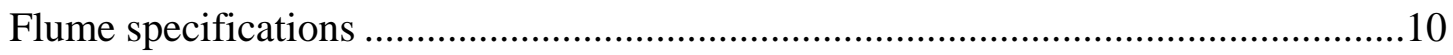

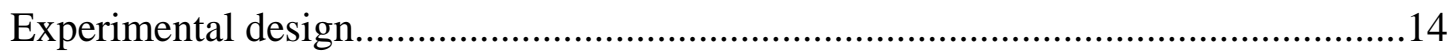

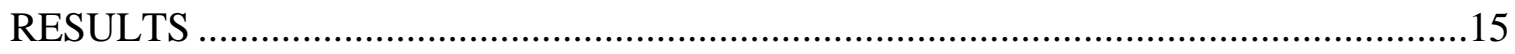

The negative relationship between transport distance and sediment

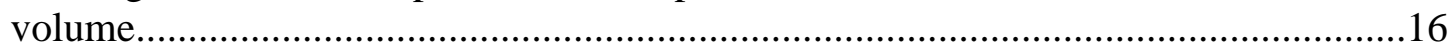

Was sediment volume too low to observe the shift to granular flow?......................19

Statistical comparison of the flume experiments ..................................................19

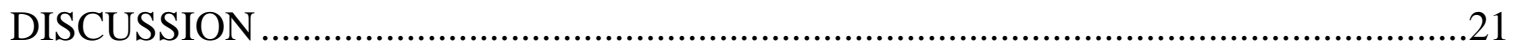

An analysis of friction on the disentrainment of mobile particles ............................21

Comparison of the mechanisms governing transport in the 1-by-1 and

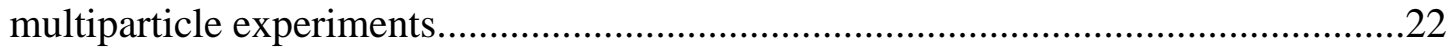

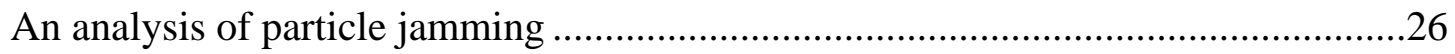

Sediment volume effects on the transition between friction-controlled gentle slopes and inertia-driven steep slopes ..................................................27

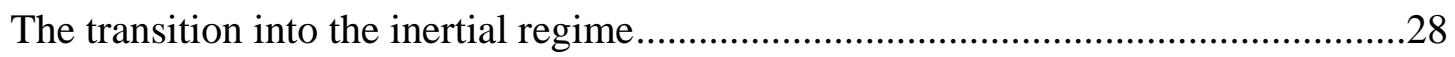

Evaluation of the multiparticle transport distance equation ....................................37

The significance of multiparticle flume experiments and further studies..................41

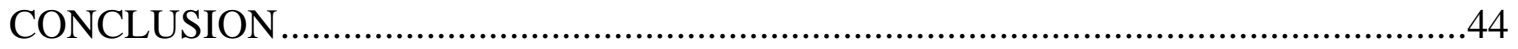

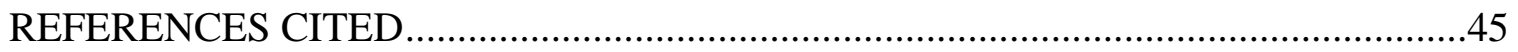




\section{LIST OF FIGURES}

Figure 1. General shape of hillslope evolution profiles predicted by linear and nonlinear diffusion

Figure 2. Schematic diagram of the dry ravel flume .............................................12

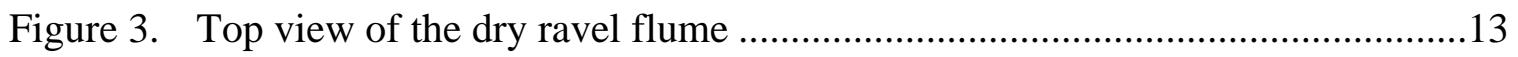

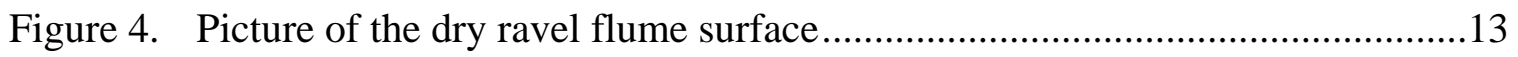

Figure 5. Sediment volume vs. transport distance based on data collected from the multiparticle experiment

Figure 6. Sediment volume vs. transport distance based on data collected from the 1-by-1 experiment......

Figure 7. Transport distances vs. sediment volume at 10 degrees based on data collected from the multiparticle experiment.

Figure 8. Comparison of the multiparticle and 1-by-1 experiments at 5 degrees .23

Figure 9. Comparison of the multiparticle and 1-by-1 experiments at 10 degrees .........24

Figure 10. Comparison of the multiparticle and 1-by-1 experiments at 15 degrees .........25

Figure 11. Transport distance histogram when $\mathrm{P}=25$ at 5 degrees.............................29

Figure 12. Transport distance histogram when $\mathrm{P}=50$ at 5 degrees.............................30

Figure 13. Transport distance histogram when $\mathrm{P}=25$ at 10 degrees............................. 31

Figure 14. Transport distance histogram when $\mathrm{P}=50$ at 10 degrees...........................32

Figure 15. Transport distance histogram when $\mathrm{P}=25$ at 15 degrees...........................33

Figure 16. Transport distance histogram when $\mathrm{P}=50$ at 15 degrees............................34

Figure 17. Transport distances vs. sediment volume at 10 degrees in which the initial velocity of $0.7 \mathrm{~m} / \mathrm{s}$ was doubled $(1.4 \mathrm{~m} / \mathrm{s})$ 
Figure 18. Multiparticle experiment: observed vs. predicted transport distance

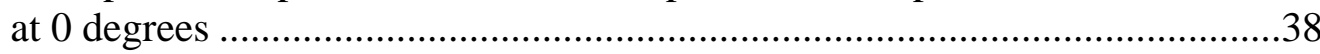

Figure 19. Multiparticle experiment: observed vs. predicted transport distance

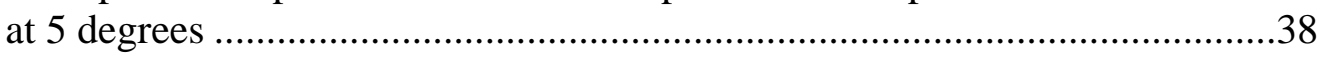

Figure 20. Multiparticle experiment: observed vs. predicted transport distance at 10 degrees

Figure 21. 1-by-1 experiment: observed vs. predicted transport distance at 5 degrees

Figure 22. 1-by-1 experiment: observed vs. predicted transport distance at 10 degrees

Figure 23. Transport distance vs. slope of the observed and predicted transport distance data collected in the multiparticle experiments $(\mathrm{K}=0.25, \mathrm{n}=0.35)$

Figure 24. Transport distance vs. slope of the observed and predicted transport distance data collected in the 1-by- 1 experiments $(K=0.05, \mathrm{n}=0.3)$ 


\section{INTRODUCTION}

\section{Hillslope sediment transport}

Sediment transport is one of the central topics of geomorphology. It has been determined that landscape form is intrinsically controlled by sediment transport. Hence, the efforts to understand the fundamental nature of landscapes requires the identification and quantification of the underlying mechanisms controlling sediment transport. Early studies quantifying sediment transport assumed a linear relationship between sediment flux and slope, otherwise known as linear diffusion (Culling, 1965). The linear relationship between sediment flux and slope was based on the assumptions that (1) sediment flux could be approximated by assuming that soils were a continuum, and that (2) local sediment flux could be determined by the local slope gradient (Tucker and Bradley, 2010). The linear diffusion model simplified the complex mechanisms governing sediment transport and thus did not incorporate complicated particle-based physics. Hillslope evolution models based on linear diffusion displayed (1) a linear increase in slope with downslope distance and (2) constant curvature along the hillslope

profile (Foufoula-Georgiou et al., 2010). The predicted hillslopes accurately reproduced profiles near the ridgetops; however, as slopes steepened downslope, the model became increasingly inaccurate. Indeed, linear flux laws predicted slopes that infinitely steepen, whereas in reality soil-mantled hillslopes straighten downslope reaching a relatively constant gradient (Fig. 1). 


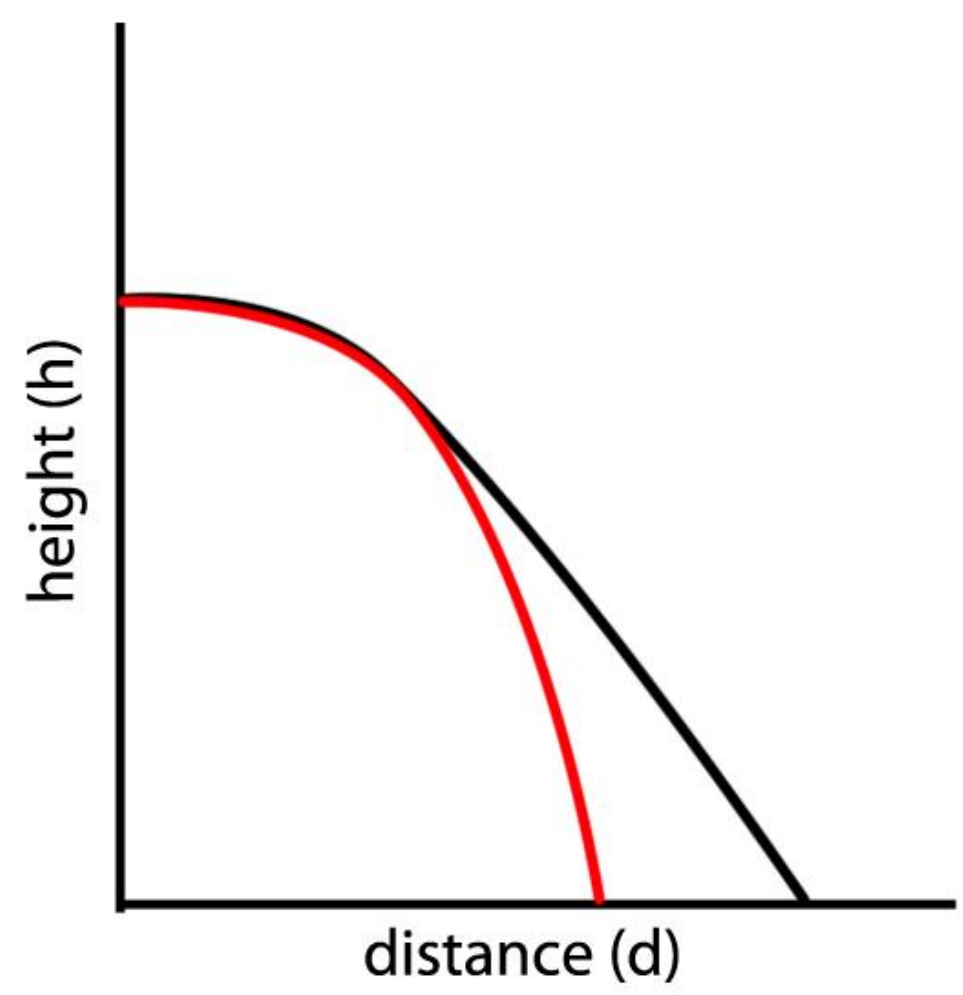

Figure 1. General shape of hillslope evolution profiles predicted by linear and nonlinear diffusion (Culling, 1965; Roering et al., 1999). The linear relationship is shown in red and the nonlinear relationship is shown in black. 
Hence, linear transport equations produced hillslope profiles that were inconsistent with the morphology of real soil-mantled hillslopes. As a result, other approaches were needed.

Subsequent studies revealed that sediment flux increases nonlinearly as slopes reach a critical gradient (Roering et al., 1999; Gabet, 2003). Hillslope profiles modeled with the nonlinear transport equations predicted more realistic hillslope profiles (Fig. 1), but they could not reproduce straight mid-slopes (Roering et al., 1999; Gabet, 2003). Indeed, these models were limited because the local sediment flux varied downslope and thus the curvature of the hillslope profile could never be zero. As slopes steepened, sediment flux became more influenced by disturbances upslope and less dependent on local slope (Foufoula-Georgiou et al., 2010; Tucker and Bradley, 2010; Mendoza and Gabet, 2012). Thus, the underlying assumptions made by Culling (1965) became increasingly invalid (Tucker and Bradley, 2010). Alternative descriptions of sediment transport were necessary to model slopes above the angle of repose.

Culling (1965) and Roering et al. (1999) assumed a deterministic relationship between slope and sediment flux, which suggested that no randomness existed in the system. In other words, given the same set of conditions and parameters, the results would always be the same. However, sediment transport processes do not behave deterministically. Take for example the rolling of particles down a rough inclined plane; deterministic models suggested that particles would always follow the same path if the initial conditions were the same (e.g., position on the slope). However, particle trajectories exhibit randomness, as evidenced by particles travelling different paths and 
distances. Consequently, more recent studies have recognized that transport distances are not deterministic (Furbish and Haff, 2010; Tucker and Bradley, 2010; Mendoza and Gabet, 2012).

Furbish and Haff (2010) showed that sediment flux is proportional to the product of soil thickness and slope gradient and that sediment flux is linearly dependent on local slope. Alternatively, Foufoula-Georgiou et al. (2010) determined that linear nonlocal transport could account for the nonlinear dependency of sediment flux. Interestingly, despite the linear relationship between sediment flux and slope gradient, both models reproduced the nonlinear hillslope profile proposed by Roering et al. (1999) and straight mid-slopes. Moreover, other probabilistic analyses that accounted for individual grain dynamics also reached similar conclusions (Tucker and Bradley, 2010; Mendoza and Gabet, 2012). These statistical approaches are imperfect, but they offered a unique insight into the probabilistic components of the system.

The need for more detailed descriptions of the mechanisms governing sediment transport prompted some studies to diverge from the traditional continuum paradigm to a particle-based approach (Tucker and Bradley, 2010; Mendoza and Gabet, 2012). The incorporation of particle dynamics into sediment flux laws was useful to define the physical mechanisms controlling sediment transport. This coupling is unique because the relationship between particle mechanics, sediment flux, and hillslope morphology was emphasized. Tucker and Bradley (2010) developed a computer simulation of interacting particles based on a predefined set of rules, which yielded realistic hillslopes with convex hilltops and straight midsections similar to the hillslope profiles modeled by other studies 
(Foufoula-Georgiou et al., 2010; Furbish and Haff, 2010). Tucker and Bradley's (2010) study reinforced the idea that nonlinear dependency leads to nonlocal control of flux (Foufoula-Georgiou et al., 2010; Mendoza and Gabet, 2012). These recent studies represent important steps toward more realistic descriptions of sediment transport.

\section{Dry ravel}

Dry ravel is the process of the downslope movement of individual particles by rolling, sliding, and bouncing as a result of gravitational force (Rice, 1982) and is the dominant sediment transport process in steep and semi-arid environments (Anderson et al., 1959). For soil creep processes such as dry ravel, sediment flux is slope dependent (Gabet, 2003). However, sediment volume may also play an important role in transport distances (Campbell, 1990). Campbell (1990) proposed that the mobilization of landslides could be explained by a layer of agitated particles that fluidizes the bulk above it. Granular temperature describes the state of this system. Thus, increased sediment volume could theoretically reduce the friction between particles and lead to greater transport distances. Typically, dry ravel is a chronic process consisting of a few particles, but after fires, dry ravel can consist of many particles. Literature on long run-out landslides reveals that increased sediment volume and the interaction of mobile particles could impact transport distances (Campbell, 1990). Thus, I suggest that transport distance is volume-dependent and that transport of dry ravel particles after fires behaves like granular flows. 


\section{Granular flows}

Landslides, debris flows, and dry ravel are sediment transport processes that may involve the flow of dry granular material. Granular material can be defined as a large assemblage of particles that lack cohesion (e.g., sand, rice, nuts) (Campbell, 1990). These granular materials are complex because they behave very differently depending on their energy level. At low energy, the granular material mimics a solid whereas at high energy it behaves like a gas (Forterre and Pouliquen, 2008). In between these two phases, the granular material flows like a liquid (Forterre and Pouliquen, 2008). This liquid phase, also known as granular flow, is significant for the purpose of understanding the multiparticle physics of processes such as dry ravel.

Typically, quantitative descriptions of granular flows center on the assumption that the granular material is a continuous mass simply sliding down an inclined surface (Savage and Hutter, 1989). This continuum approach is valid under the assumption that the flowing layer is thin compared to its lateral extension (Pouliquen and Forterre, 2002). For processes such as dry ravel, this assumption is reasonable, because the flowing layer is thin in comparison to the hillslope length. Current descriptions of granular flows suggest that transport is controlled by a balance between kinetic energy, loss of momentum from collisions, and the roughness of the inclined plane (Forterre and Pouliquen, 2008).

Previous literature revealed that granular flows on an inclined plane cannot be approximated by friction alone (Savage and Hutter, 1989). Indeed, one flaw with the 
simple friction law is that hysteresis cannot be accounted for. That is, in a steady state system, the slopes required to mobilize particles and to stop the mobilized particles are different. Once static particles are mobilized at a given slope, a lower slope is required to stop the particles. This hysteresis indicates that there must be other controls besides friction. Indeed, granular flows are dependent on both the slope and the thickness of the layer of granular material (Savage and Hutter, 1989; Pouliquen, 1999; Iverson and Denlinger, 2001; Pouliquen and Forterre, 2002; Iverson et al., 2004). Therefore, the slope in which static particles are mobilized is dependent on the thickness of the granular material. At steady state, mobile granular flows can be in motion with a constant velocity because of the equilibrium of energy going into the system and leaving the system (Quartier et al., 2000). In other words, the potential energy due to gravity and the kinetic energy of the mobile particles are balanced by the energy lost by friction.

For the process of dry ravel, quantification of the transition from static (solid) to inertial (liquid) regimes is essential. At low energy, the granular material mimics a solid and its strength is primarily a result of its structural configuration. At static state, particles interlock with surrounding particles forming force chains that inhibit flow (Campbell, 2006). However, once the force chains are broken the granular material can mobilize. Due to the structural strength of the force chains, the slope required to mobilize granular material in the solid state must be greater than the slope required to stop the granular material. At relatively low energy (e.g., low slopes), particles are unable to overcome the force chains and the material remains static. At higher energy (e.g., steeper slopes, greater velocity), the force chains can be broken and thus the 
granular material is able to flow. During mobilization, the granular material can move slightly and stop, thereby creating new sets of force chains. However, if there is sufficient energy in the system (e.g., steeper slopes, greater velocity), the particle to particle contact becomes increasingly intermittent, which decreases the likelihood of the formation of new force chains. Thus, granular materials could mimic a liquid in high energy environments.

\section{Flume experiments}

Past studies have demonstrated that the motion of a particle raveling down a rough surface could be approximated as a block sliding down an inclined plane (Kirkby and Statham, 1974; Statham, 1976; Gabet, 2003; Mendoza and Gabet, 2012). These studies suggested that particle movement is a Poisson process controlled by the probabilities of stopping, and transport distance could be defined by

$$
d=\frac{v_{o}^{2}}{-2 a}
$$

where $v_{0}$ is the initial velocity $(\mathrm{m} / \mathrm{s}), a$ is the acceleration of the particle $\left(\mathrm{m} / \mathrm{s}^{2}\right)$. The acceleration of a single particle is calculated by

$$
a=g(\sin \theta-\mu \cos \theta)
$$

where $\mathrm{g}$ is gravity $\left(\mathrm{m} / \mathrm{s}^{2}\right), \mu$ is a friction coefficient, and $\theta$ is the slope angle (degrees). The average transport distance of particles can be calculated using the following equation (Gabet, 2003) 


$$
d=\frac{v_{0}^{2}}{2 g(\mu \cos \theta-\sin \theta)}
$$

Mendoza and Gabet (2012) examined single particle dynamics to model dry ravel. They showed that, at steeper slopes, the length of the contributing area upslope becomes increasingly important. They determined that the angle of repose represents a shift between friction-controlled shallow slopes dominated by local transport, and inertiadriven steep slopes dominated by nonlocal transport. This dry ravel flume experiment offered a unique analysis of particle dynamics in relation to sediment transport; however, soil creep processes such as dry ravel typically involve more than one particle. Thus, a better understanding of dry ravel mechanics required an examination of multiparticle transport and the transition into granular flow.

To expand on the recent work on particle transport by Mendoza and Gabet (2012), I conducted a flume experiment investigating the mechanics of multiparticle transport and examined the transition from particle-to-particle transport to granular flow. I hypothesized that transport distance was a function of sediment volume and that some portion of the observed nonlinearity at steep slopes was an effect of sediment volume. I approached this experiment by conducting a flume experiment in which I dropped particles onto the flume and measured transport distances. I performed (1) a momentum analysis, and (2) a sediment volume analysis.

At shallow slopes, the momentum was low, which resulted in friction-dominated transport, whereas at steep slopes, increased momentum led to inertia-dominated transport. The acceleration of the dropped particles increased as slopes steepened and thus greater potential energy resulted in greater kinetic energy (Eq. 2). Hence, granular 
force chains were easier to overcome at greater slopes. In this experiment, the dropped particles were already mobile so force chain effects were not examined. However, hysteresis, the concept that the granular flow could stop at a gentler slope than the mobilization slope is important. As slopes steepened, particles were more likely to become suspended such that contact with the flume surface became more intermittent, which effectively reduced friction and led to greater transport distance. On real hillslopes, multiple layers of particles interact, but in this experiment, a single layer of particles was examined to analyze the effect of inter-layer particle collisions on transport distance. As the sediment volume increased, more particles were available to interact with each other.

I hypothesized that, at a given slope, increased sediment volume would result in greater average transport distance. I proposed that increased particle collision would cause the particles to vibrate and therefore reduce contact with the flume surface. The reduction of particle-to-flume contact would decrease the effective surface friction and lead to greater transport distances.

\section{MATERIALS AND METHODS}

\section{Flume specifications}

A 3-m-long, 0.15-m-wide wooden box was used as the base of the flume and was filled with concrete and shaped into a half-pipe surface. The narrow flume and the 
curved sides ensured that the particles interacted consistently as they travelled downslope. A 10-cm-diameter acrylic tube was attached to one end of the flume and used as the sediment chamber. The tube was partially cut so that an acrylic slot could be inserted to trap particles and pulled to release the particles onto the flume (Fig. 2).

Crushed gravel (1-cm diameter) was used to simulate individual dry ravel particles.
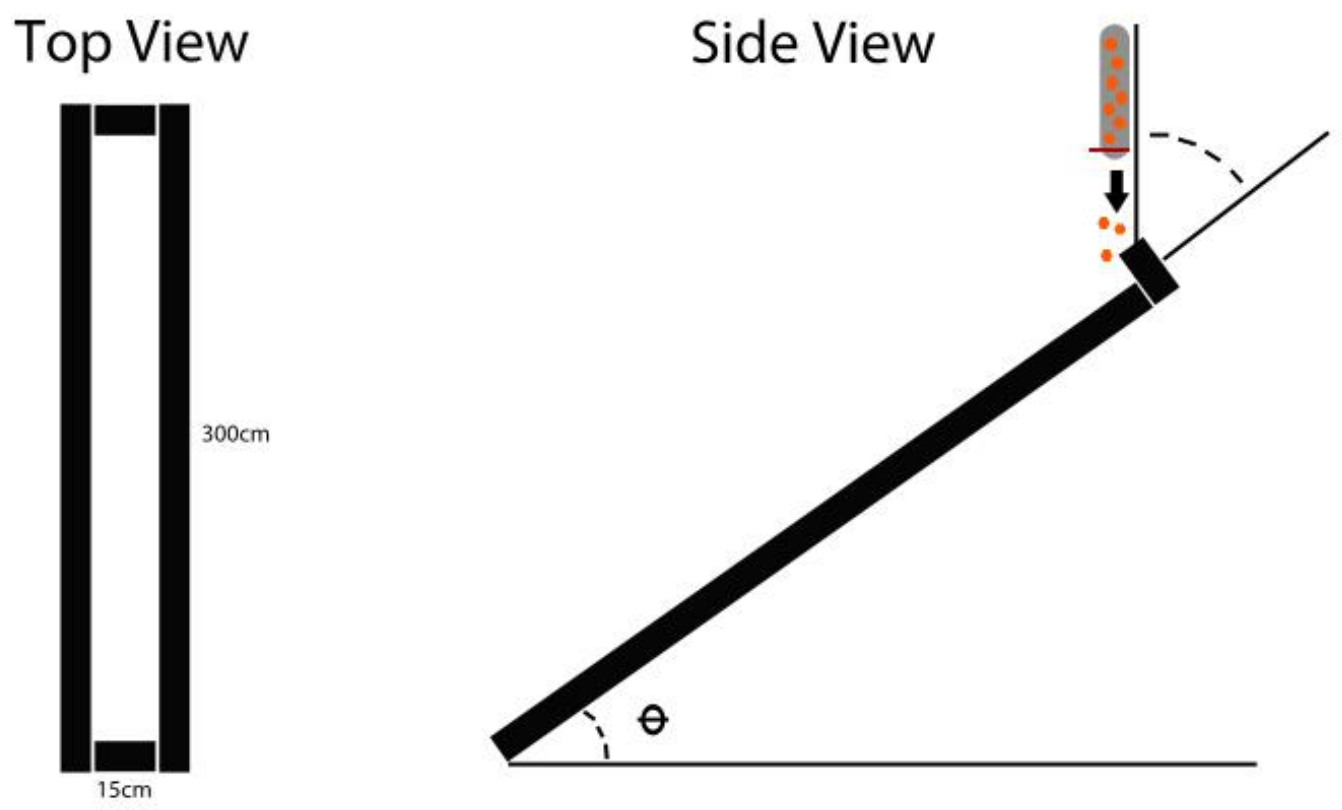

Figure 2. Schematic diagram of the dry ravel flume (not to scale). 
A folding hinge was installed to precisely control the angle between the flume and the sediment chamber (Fig. 2). An $11^{\circ}$ ramp was installed into the base of the flume right below the sediment chamber. Particles were dropped vertically and travelled down the flume once contact was made with the ramp. The initial velocity $(\mathrm{m} / \mathrm{s})$ of the mobile particles could be determined by

$$
v_{0}=\sqrt{2 g h} \sin (\theta+11)
$$

where $\mathrm{h}$ is height $(\mathrm{m})$. Sediment flux $\left(\mathrm{m}^{2} / \mathrm{s}\right)$ is defined as

$$
q_{s}=\frac{V d}{A t}
$$

where $\mathrm{V}$ is cross-sectional volume $\left(\mathrm{m}^{3}\right)$, $\mathrm{A}$ is cross-sectional area $\left(\mathrm{m}^{2}\right)$, and $\mathrm{t}$ is time $(\mathrm{s})$. The cross-sectional volume is simply the cross-sectional area multiplied by the thickness of the particle. Instantaneous sediment flux $\left(\mathrm{m}^{2} / \mathrm{s}\right)$ is defined as

$$
q_{s}=\frac{V v}{A}
$$

where $v$ is velocity $(\mathrm{m} / \mathrm{s})$. The area of the flume is constant, thus, the instantaneous sediment flux is simply a function of volume and velocity. In this experiment, particles were dropped at different elevations depending on the slope of the flume to maintain constant initial velocity. Therefore, the sediment volume variable was isolated and sediment volume effects on sediment flux could be examined. 
In the initial flume design, the half-pipe-like flume surface was implemented to maximize particle interaction on the flume surface. However, the experiments revealed that particles were getting trapped behind other particles in the front and typically travelled and were deposited in a single and relatively straight line (e.g., single lane traffic jam). The flume was later modified by filling the half pipe to the width of the ramp to mimic a more realistic dry ravel bed (Figs. 3-4).

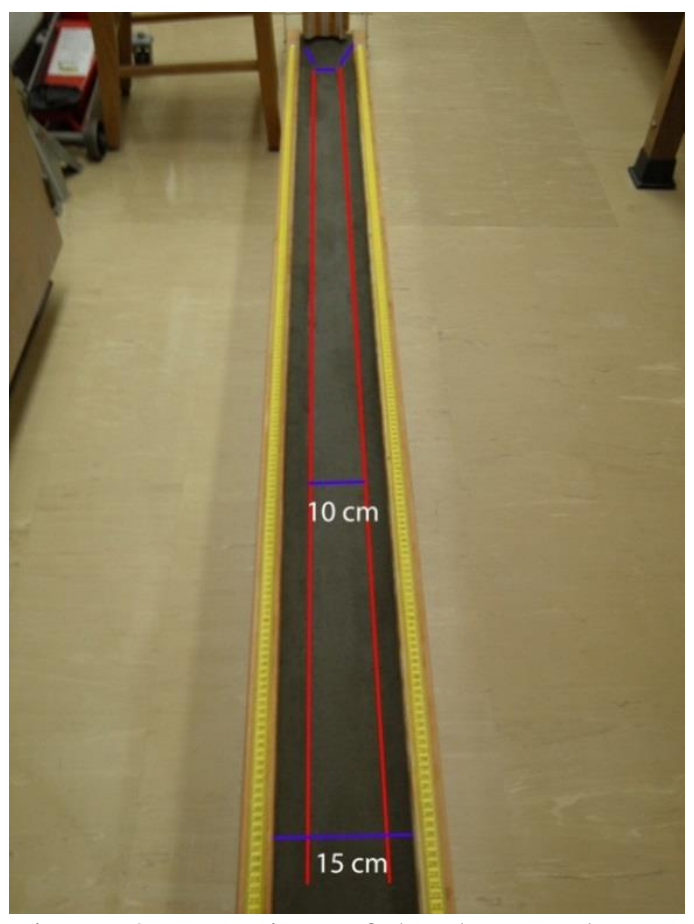

Figure 3. Top view of the dry ravel flume. An outline of the flume ramp is marked in blue and the flat flume surface is marked in red.

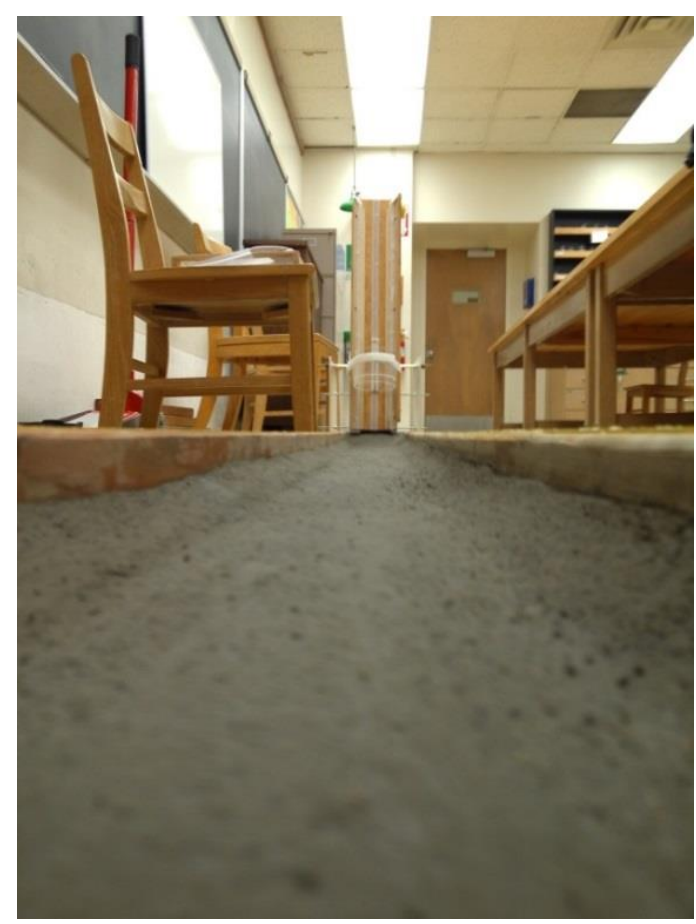

Figure 4. Picture of the dry ravel flume surface. The sides of the flume are slightly curved to prevent particle collision with the wooden sides of the flume. The clear acrylic sediment chamber can be seen in the background. The sediment chamber is strapped by Velcro so that the elevation can be adjusted. 


\section{Experimental design}

Varying amounts of sediment particles were released at varying slopes of the

flume. For each slope setting, simulations were conducted with 1, 10, 25, and 50

particles. The slope of the flume was increased by increments of 5 degrees starting at 0 degrees and up to 15 degrees. At 20 degrees, the majority of the particles hit the end of the flume so transport distances could not be measured. The initial velocity of the dropped particles was held constant throughout all slope settings, but acceleration increased as slopes steepened. Mendoza and Gabet (2012) determined that there was a transitional slope that separates friction-controlled gentle slopes and inertia-driven steep slopes. I hypothesized that the shift between the frictional and inertial regimes correlates with the shift from a static granular solid to granular flow. In this view, the transitional slope would be marked by a stark difference in the average transport distance.

In reality, dry ravel can be mobilized as a single particle or as a group of particles. Two distinct flume experiments were performed to examine multiparticle transport. In one of the experiments, particles were dropped together in groups of $1,10,25$, and 50 . In the other experiment, particles were dropped one by one, and the stopped particles were left on the flume while subsequent particles were dropped. These experiments are referred to as the multiparticle and 1-by-1 experiments, respectively. Transport distances were recorded at $1,10,25$, and 50 particle intervals. Generally, a single simulation can be summarized by: (1) setting the slope angle, (2) placing the sediment chamber at the correct elevation to control for the initial velocity, (3) loading particles into the sediment 
chamber, (4) adjusting the angle of the sediment chamber to be vertical, (5) releasing the particles onto the flume, and (6) recording the transport distance of each individual particle.

\section{RESULTS}

The acceleration equation (Eq. 2) was modified to account for multiple particle dynamics

$$
a=g(\sin \theta-\mu \cos \theta)-K\left(\frac{D(P-1)}{W}\right)^{n}
$$

where $\mathrm{K}$ is a constant, $\mathrm{D}$ is the diameter of the particle $(m), \mathrm{P}$ is the number of particles (sediment volume), $\mathrm{W}$ is the width of the flume $(m)$, and $\mathrm{n}$ is a constant. The second term on the right hand side is basically a particle density term that accounts for particle collisions. When $\mathrm{P}$ is 1 , the term on the right hand side goes to zero which is essentially equivalent to the original acceleration equation (Eq. 2). Thus, the revised acceleration equation is applicable for all sediment volumes. The original transport distance equation (Eq. 1) was modified to account for multiparticle acceleration

$$
d=\frac{v_{0}^{2}}{2\left(g(\mu \cos \theta-\sin \theta)+K\left(\frac{D(P-1)}{W}\right)^{n}\right)}
$$




\section{The negative relationship between transport distance and sediment volume}

I hypothesized that there was a positive relationship between sediment volume and transport distance. However, experiments on the original half-pipe flume indicated a negative relationship between sediment volume and transport distance. In other words, the average transport distance decreased at greater sediment volume. I attributed the discrepancy with my hypothesis to be due to the curved nature of the flume surface which resulted in particles travelling in a single line. The flume surface was modified by partially filling in the half-pipe surface to create a flat surface that was approximately 10 cm wide (Fig. 3). The experiments were repeated on the modified flume, which confirmed the negative relationship between sediment volume and transport distance (Figs. 5-6). The flume experiment revealed that transport distances increased at steeper slopes, but decreased with greater sediment volume. 


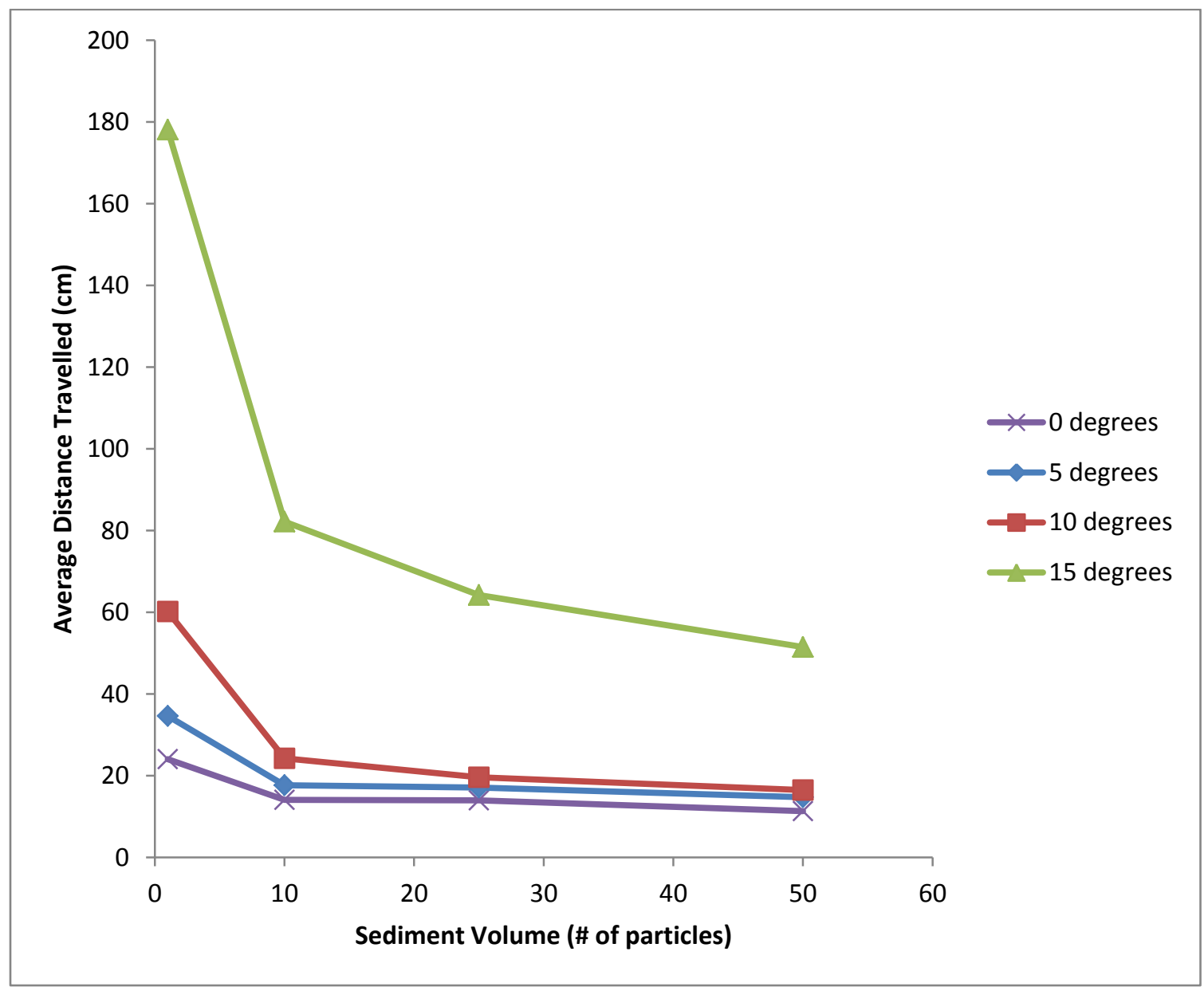

Figure 5. Sediment volume vs. transport distance based on data collected from the multiparticle experiment. 


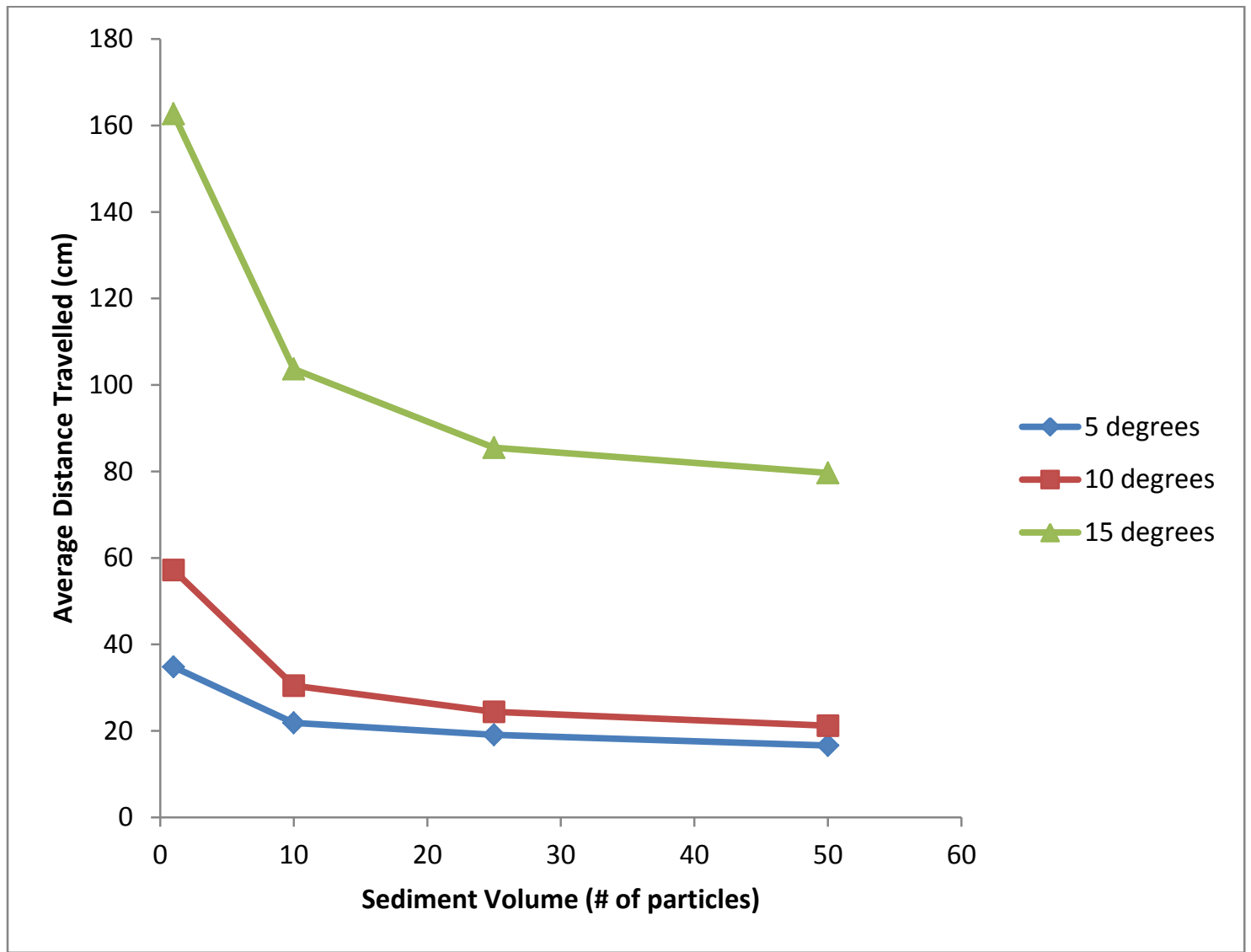

Figure 6. Sediment volume vs. transport distance based on data collected from the 1-by-1 experiment. 


\section{Was sediment volume too low to observe the shift to granular flow?}

Typically, granular flows have very high sediment volume. Thus, there is a possibility that low sediment volume prevented the shift into granular flow. Sediment volume was increased from 50 particles to 100 particles to test this hypothesis, but no indication of a positive relationship between sediment volume and transport distance was documented, but transport distances became increasingly asymptotic (Fig. 7). Greater sediment volume may be required for granular flow $(\mathrm{P}>100)$. However, further experiments were not performed due to the size limitations of the flume and the difficulty of controlling for the initial velocity at high sediment volume.

\section{Statistical comparison of the flume experiments}

At gentle slopes, the average transport distance for the 1-by-1 and multiparticle experiments are similar when $\mathrm{P}=1$ and $\mathrm{P}=50$, but slightly different when $\mathrm{P}=10$ and $\mathrm{P}$ $=25$. In the 1-by-1 experiment, transport distance decreased at a slower rate as sediment volume increased. In the multiparticle experiment, transport distance became asymptotic when $\mathrm{P}=10$ or more (Figs. 5-6). T-tests revealed that the transport distances between the 1-by-1 and multiparticle experiments were similar at gentle slopes, but they became increasingly different at steeper slopes and higher energy. The difference can be attributed to different mechanisms governing transport at gentle and steep slopes. 


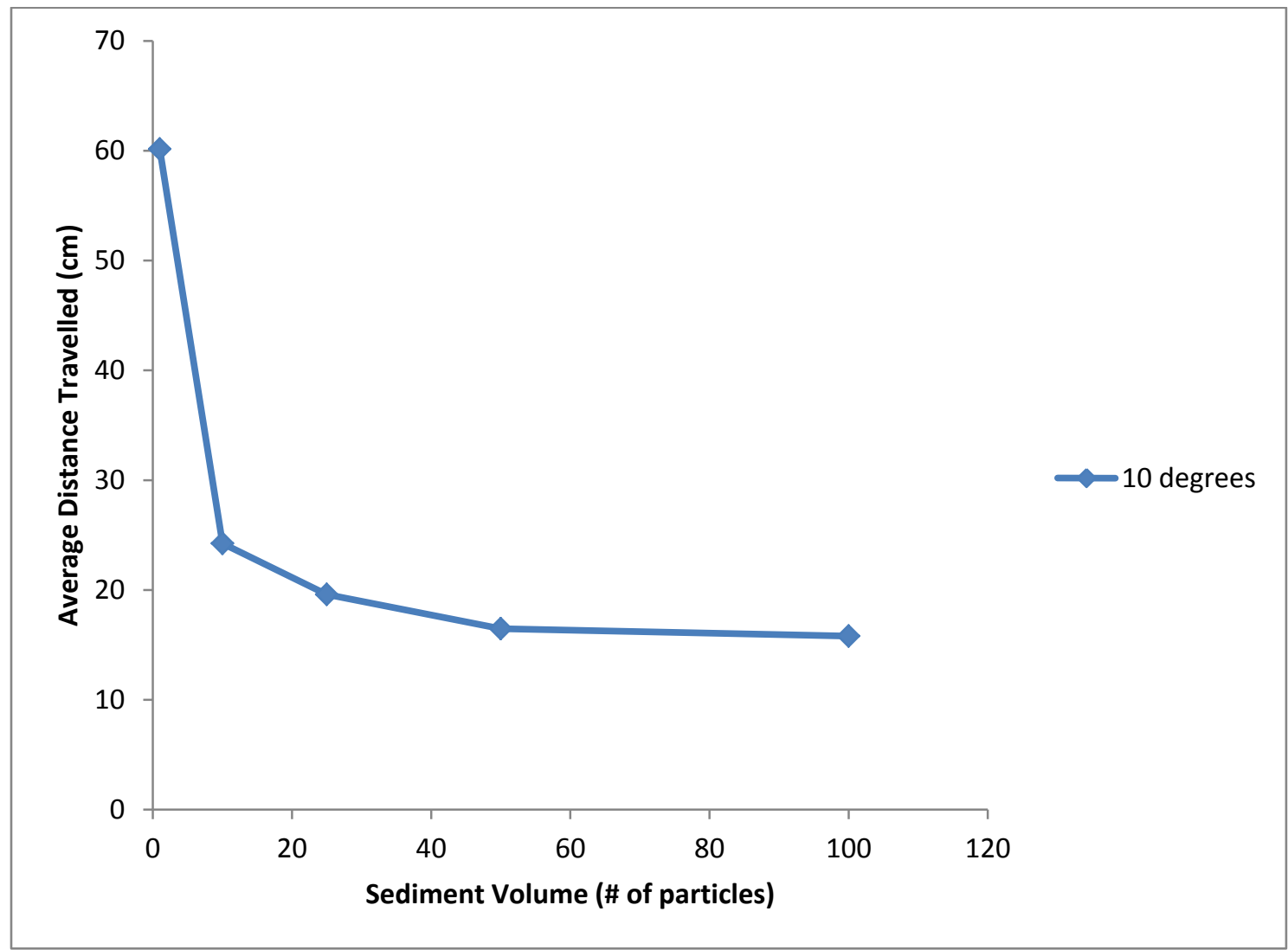

Figure 7. Transport distances vs. sediment volume at 10 degrees based on data collected from the multiparticle experiment. 


\section{DISCUSSION}

\section{An analysis of friction on the disentrainment of mobile particles}

Generally, mobile particles were disentrained as a result of frictional resistance. Three types of friction were identified in this experiment: (1) surface friction (particle friction against the surface of the flume), (2) mobile particle collision friction (interparticle friction caused by collisions between mobile particles), and (3) stationary particle collision friction (inter-particle friction caused by collisions between mobile and stationary particles). These three frictions effectively reduced transport distances and disentrained the mobile particles. In the 1-by-1 experiment, a combination of surface friction and stationary particle collision friction caused the disentrainment of the mobile particles. In the multiparticle experiment, a combination of surface friction, stationary particle collision friction, and mobile particle collision friction caused the disentrainment of the mobile particles. Hence, the difference between the 1-by-1 and multiparticle experiments is the extra mobile particle collision friction term. Therefore, transport distances were impacted by greater frictional resistance to flow in the multiparticle experiment.

When sediment volume was 1 particle $(\mathrm{P}=1)$, the particle was disentrained by surface friction alone. However, the difference in transport distances became more apparent as sediment volume increased $(\mathrm{P}>1)$. In the 1-by-1 experiment, the majority of the particles were stopped by other stationary particles on the flume. Alternatively, in the 
multiparticle experiment, the majority of the particles were disentrained by other mobile particles that blocked transport pathways downslope. In some rare instances, a few particles were able to remobilize other disentrained particles. Remobilization of disentrained particles was more common in the 1-by-1 experiment and typically occurred further down the flume than in the multiparticle experiment.

\section{Comparison of the mechanisms governing transport in the 1-by-1 and multiparticle experiments}

Sediment volume effects on transport distance were observed in both the 1-by-1 and multiparticle experiments, but at different magnitudes. Transport distances in the multiparticle experiment were consistently lower as sediment volume increased $(\mathrm{P}>1)$ (Figs. 8-10). The lower average transport distance confirmed that greater frictional resistance to flow is present in the multiparticle scenario.

In the 1-by-1 experiment, stationary particles on the flume acted as sediment barriers that impeded the path of oncoming mobile particles. In the multiparticle experiment, slower mobile particles in front jammed up the particles behind and caused disentrainment. I define jamming as the circumstance in which the particles in the front including mobile (slower particles) and non-mobile (stationary barriers) particles impeded the mobile particles behind them. As sediment volume increased, more particles were available to collide and thus the jamming effects increased. 


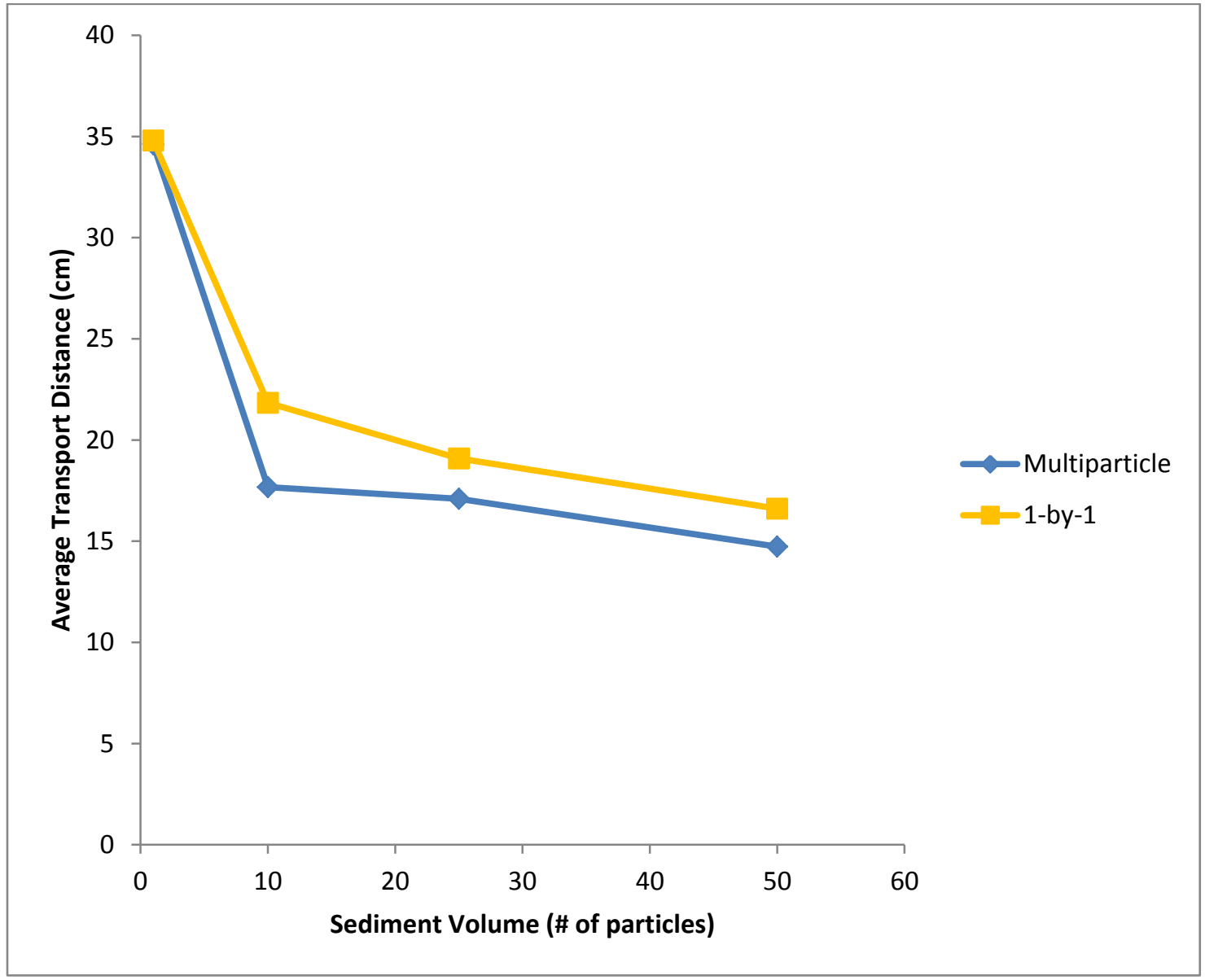

Figure 8. Comparison of the multiparticle and 1-by-1 experiments at 5 degrees. 


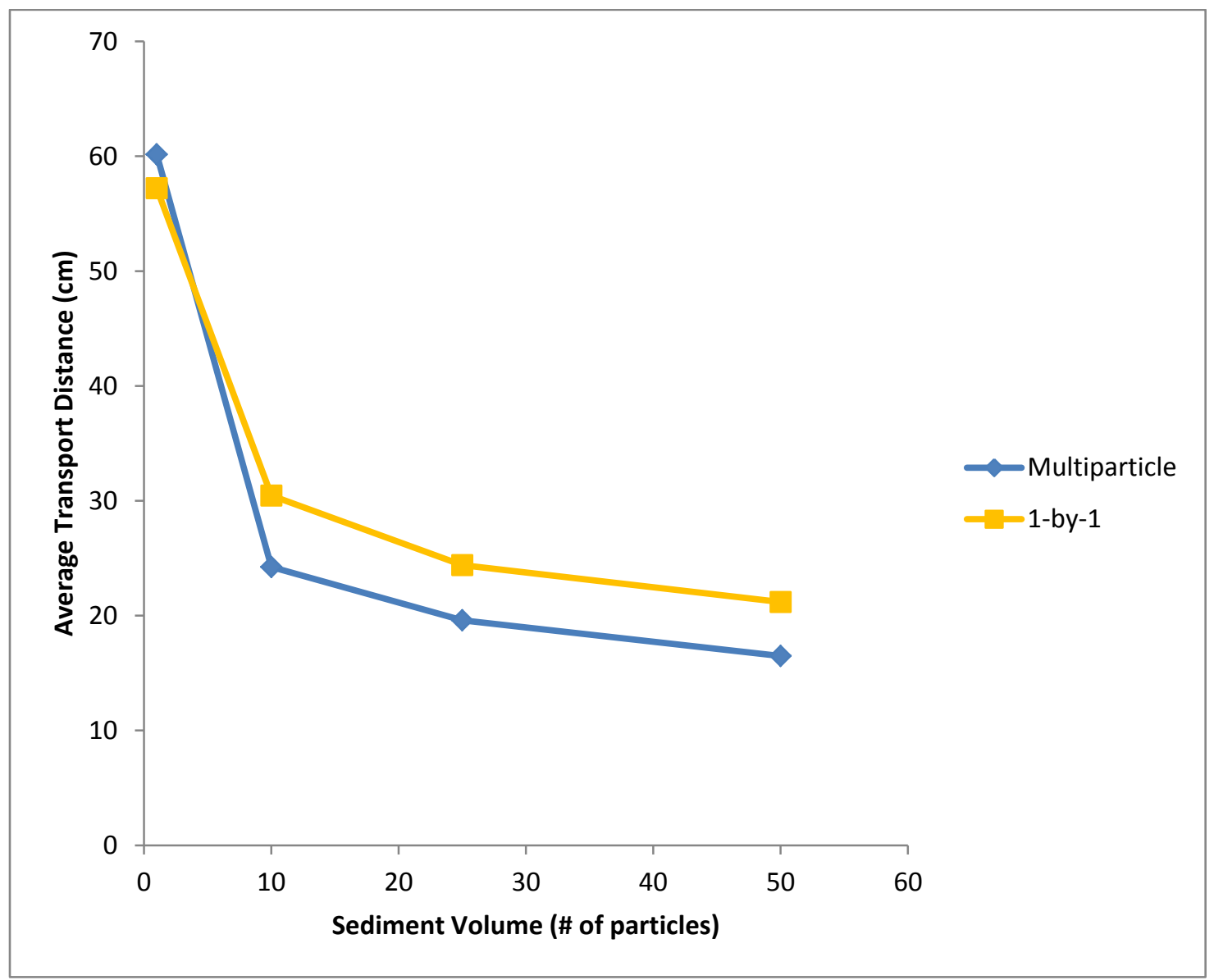

Figure 9. Comparison of the multiparticle and 1-by-1 experiments at 10 degrees. The average transport distance in the multiparticle experiment was approximately $10 \mathrm{~cm}$ less when $\mathrm{P}=10,25$, and 50 . 


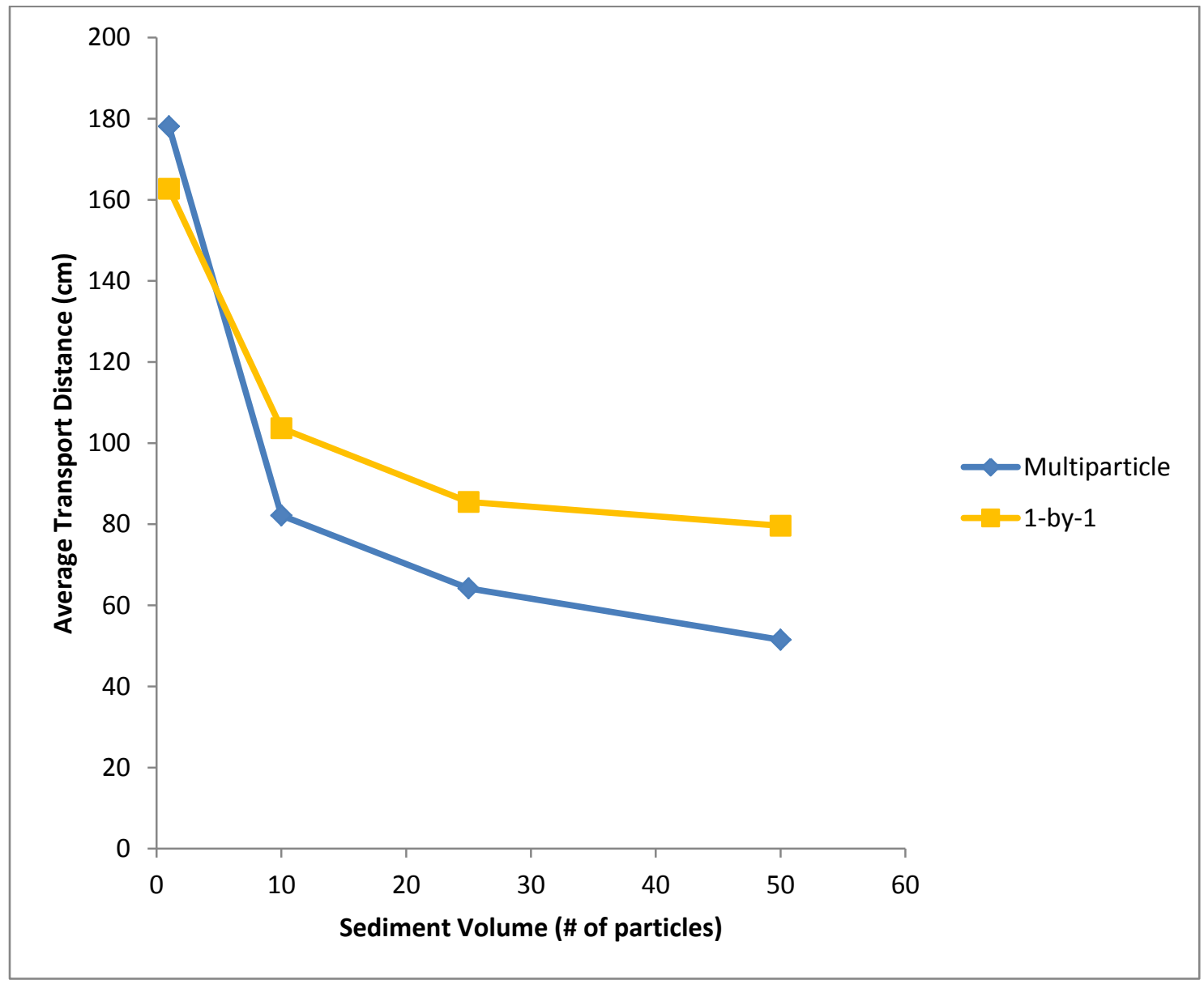

Figure 10. Comparison of the multiparticle and 1-by-1 experiments at 15 degrees. As sediment volume increased, the variance between the 1-by-1 and multiparticle experiments increased. The average transport distance for the multiparticle experiment was approximately 20-30 cm less when $\mathrm{P}=10,25$, and 50. 
Generally, transport distances decreased with each collision and it follows that transport distances decreased as sediment volume increased. Furthermore, the flume experiments revealed the importance of mobile particle collision friction and the timing of collisions. In the multiparticle experiment, mobile particles collided immediately once they were dropped onto the flume. In the 1-by-1 experiment, mobile particles collided with the stationary particles further down the flume. In this experiment, mobile particles were not immediately resisted by collisional frictions, and thus inertia built up. Greater inertia resisted disentrainment and led to greater transport distances. The buildup of inertia and timing of collisions also explain why the remobilization of disentrained particles was more common in the 1-by-1 experiment and steeper slopes.

\section{An analysis of particle jamming}

The collisional frictions cause the jamming effects that were observed in the flume experiments. In the 1-by-1 experiment, jamming can be approximated by stationary particle collision friction. In the multiparticle experiment, jamming can be approximated by a combination of stationary and mobile particle collision friction. Hence, the effect of the mobile particle collision friction term could be evaluated by comparing the 1-by-1 and multiparticle experiments.

Quantification of particle jamming is useful for predicting transport distances. In the multiparticle experiment, mobile particle collisions significantly reduced transport distance by immediately jamming the particles. Mollon et al. (2012) determined that 
particle jamming effects were amplified at the transition between two slopes. In my experiments, I observed significant jamming at the break in slope between the slope of the flume and the slope of the ramp. Furthermore, a majority of the particles stopped at the transition zone between the flume surface and ramp in the multiparticle experiment. The particles in the front got jammed up because of the break in slope, and they essentially slowed down the particles behind them.

\section{Sediment volume effects on the transition between friction-controlled gentle slopes and inertia-driven steep slopes}

The mechanisms governing transport in the 1-by-1 and multiparticle experiments were similar at gentle slope, but increasingly different at steeper slopes. Previous experiments documented that transport was governed by friction on gentle slopes and inertia on steep slopes (Mendoza and Gabet, 2012). My flume experiments revealed that the transition slope between the frictional and inertial regime increased at greater sediment volume. Therefore, more energy is necessary to transition into the inertial regime at greater sediment volume. 


\section{The transition into the inertial regime}

The distribution of transport distances for both the 1-by-1 and multiparticle experiments was positively skewed (Figs. 11-16). However, at steeper slopes the distribution of transport distances in the 1-by-1 experiment began to flatten (Figs. 15-16). In other words, a greater proportion of particles began to travel further. The flattening of the distribution of transport distances could be an indication of a shift into the inertial regime. At higher energy slopes, a greater distribution of particles travelled further, and thus, particle jamming effects appeared to be limited. I suggest two possible explanations for the greater transport distances: (1) inertial forces overcame sediment volume effects, and (2) sediment volume effects were becoming increasingly positive as transport shifted into the inertial regime. 


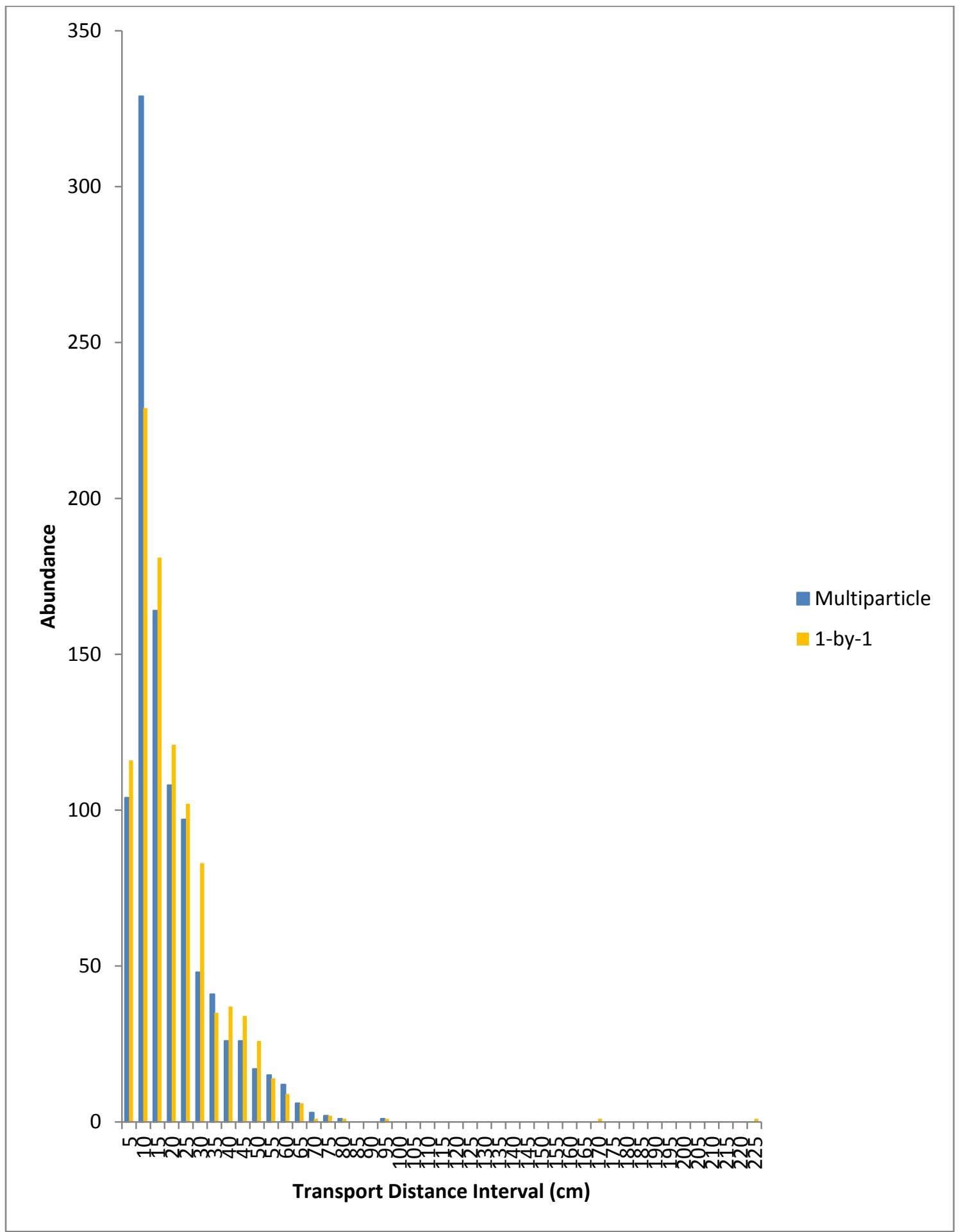

Figure 11. Transport distance histogram when $\mathrm{P}=25$ at 5 degrees. 


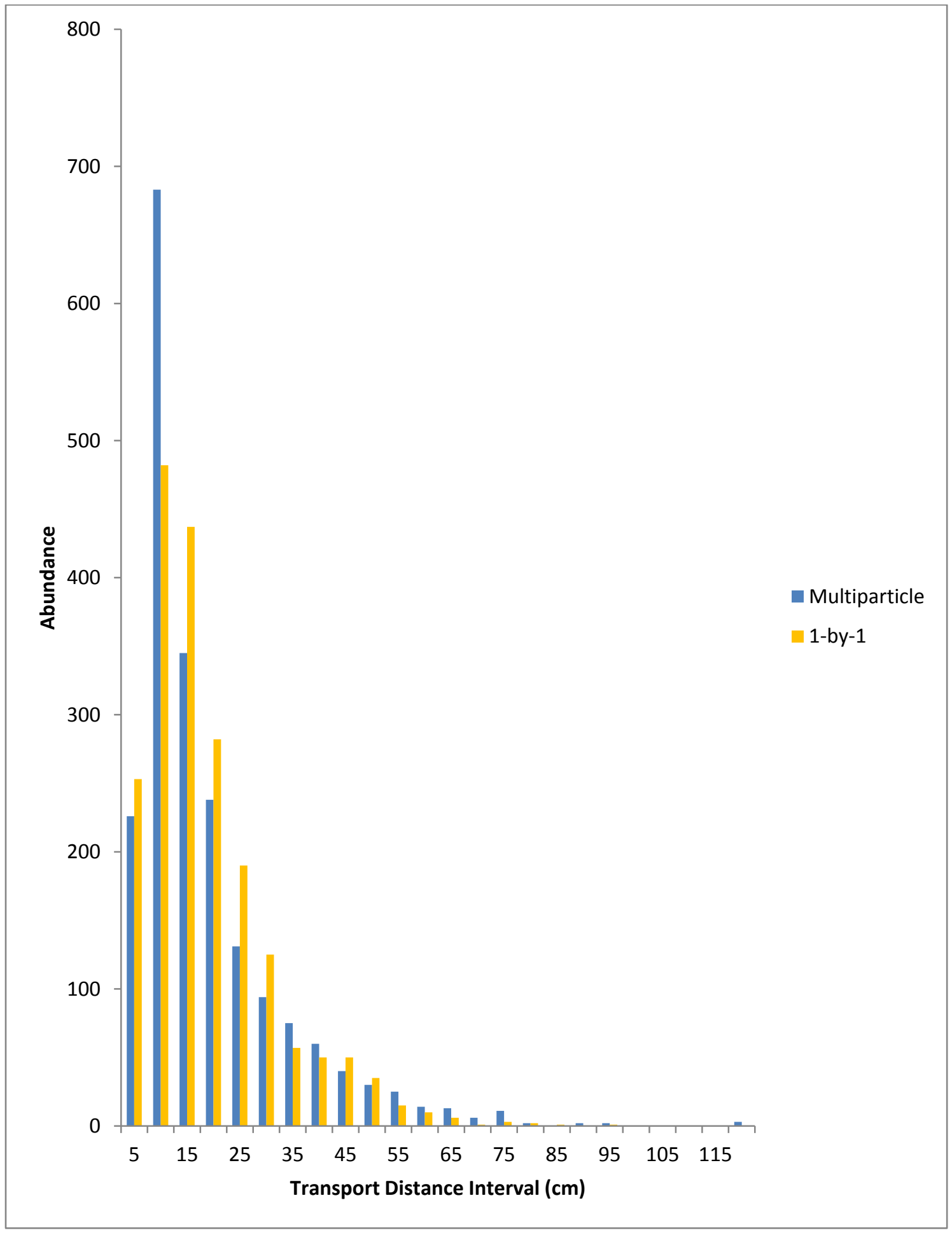

Figure 12. Transport distance histogram when $\mathrm{P}=50$ at 5 degrees. 


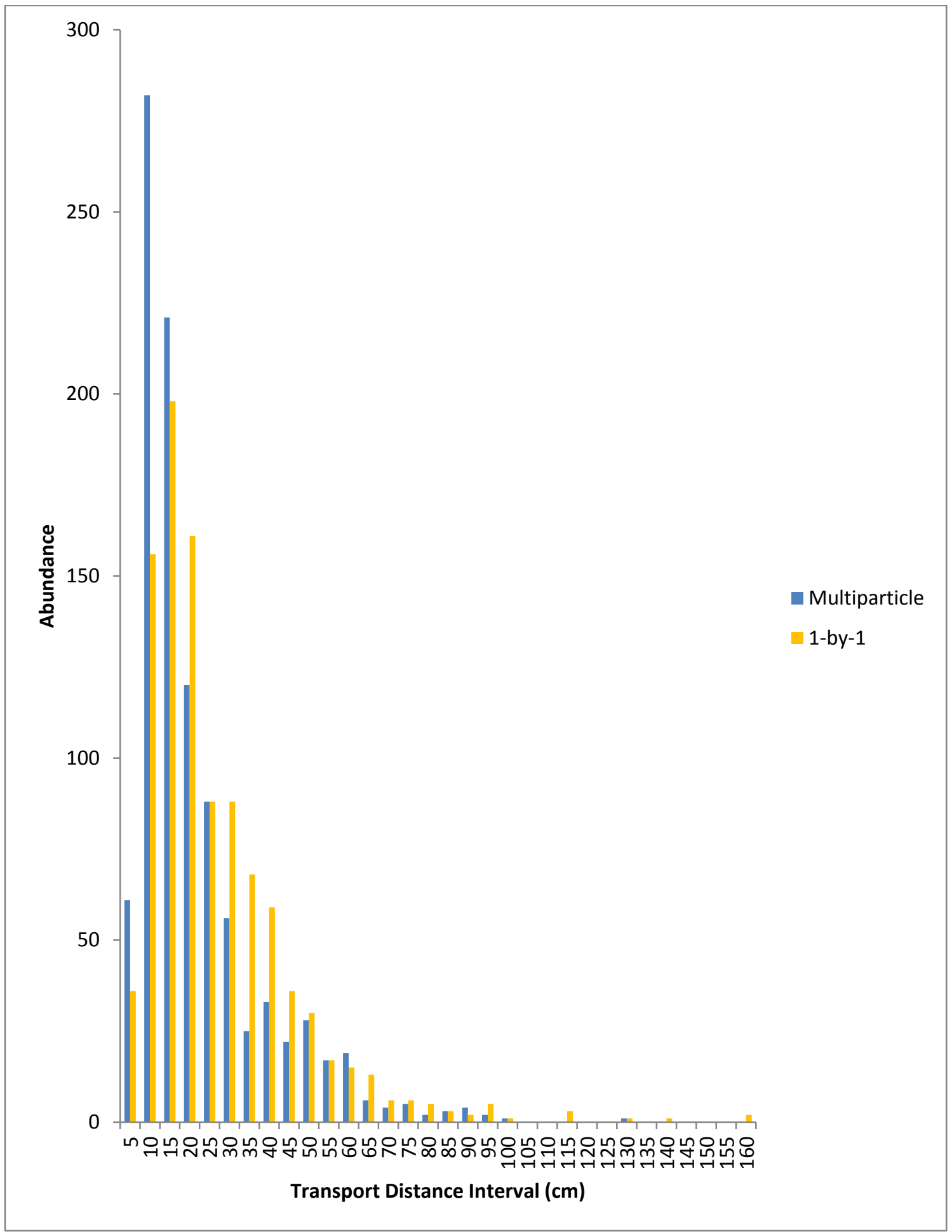

Figure 13. Transport distance histogram when $\mathrm{P}=25$ at 10 degrees. 


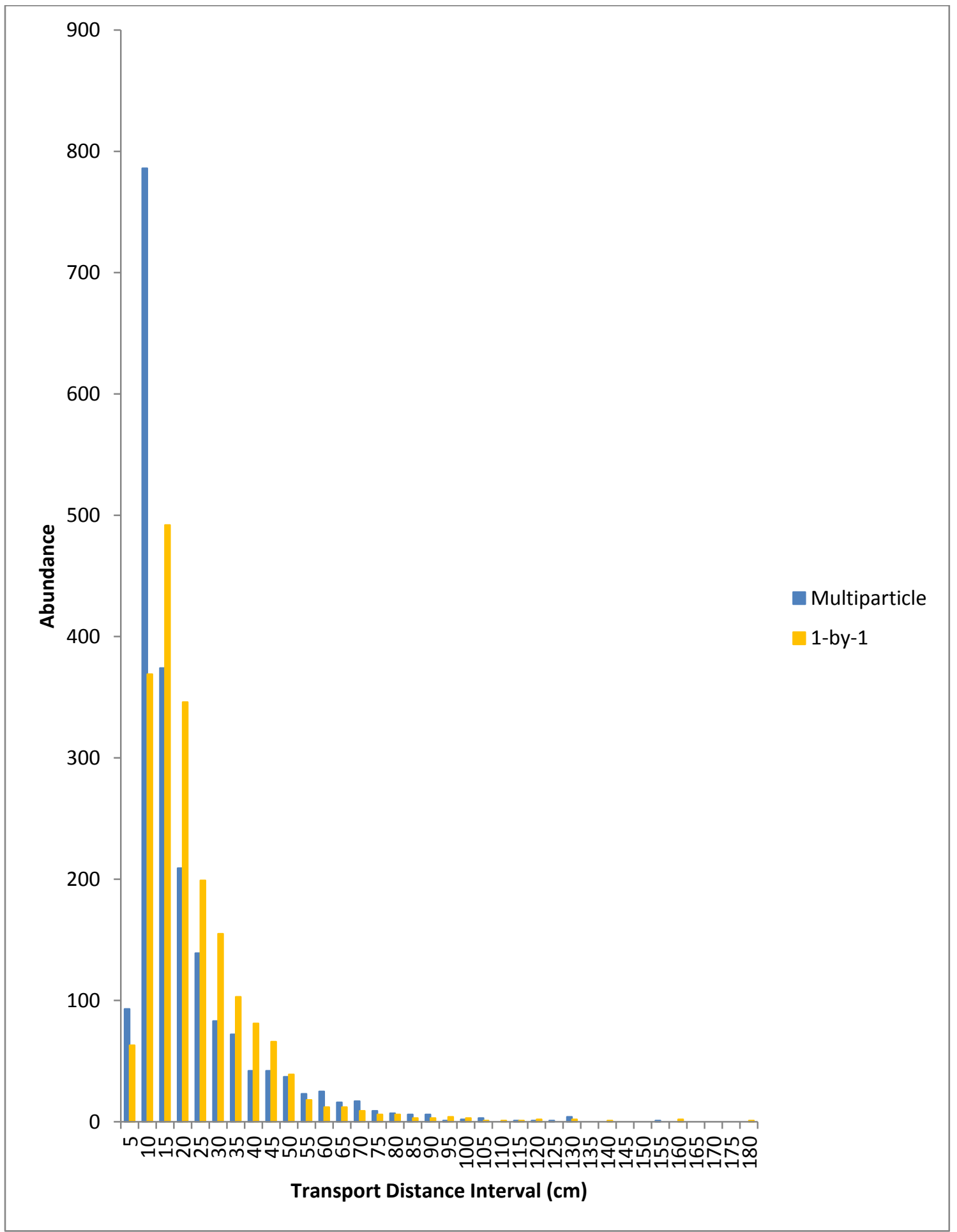

Figure 14. Transport distance histogram when $\mathrm{P}=50$ at 10 degrees. 


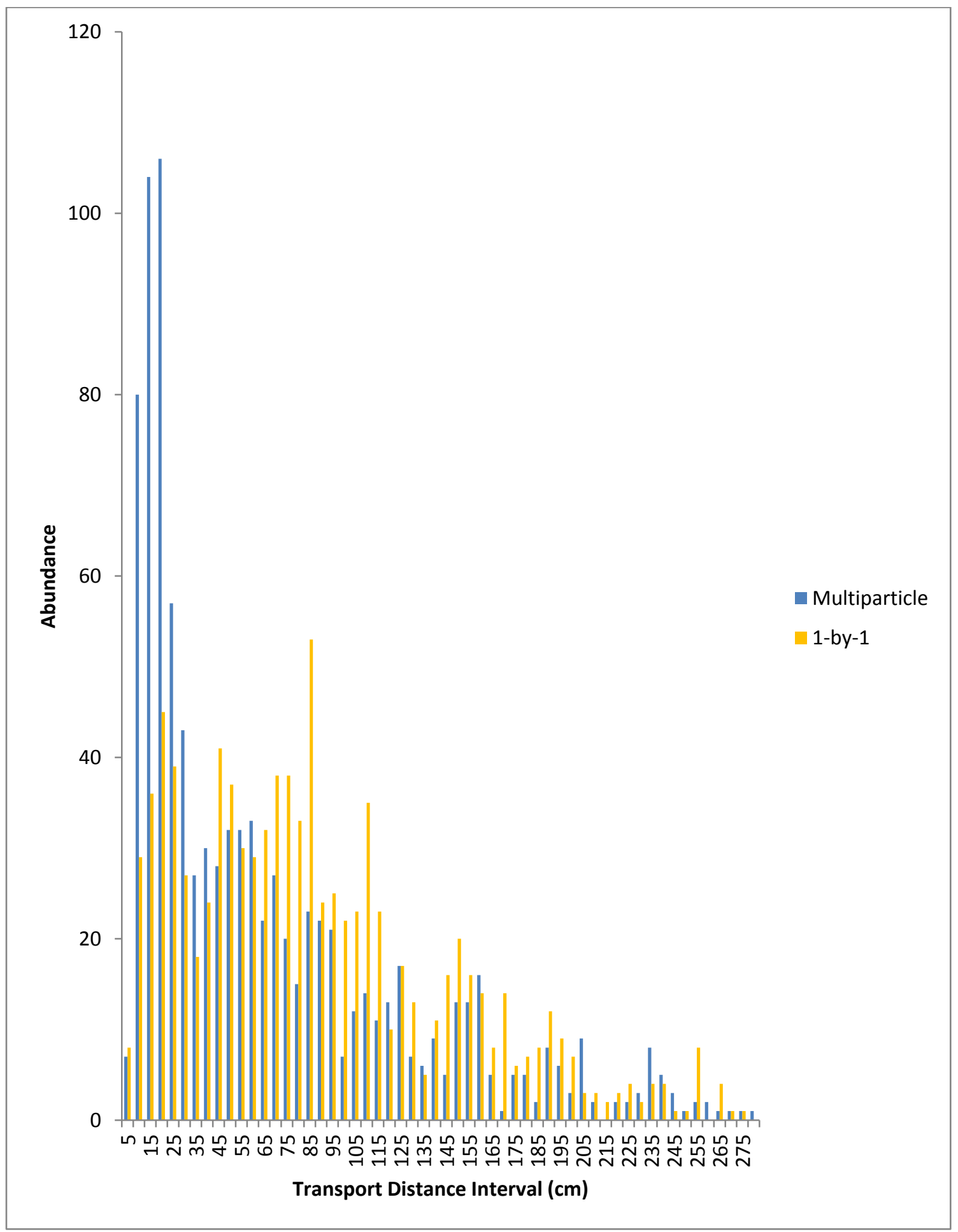

Figure 15. Transport distance histogram when $\mathrm{P}=25$ at 15 degrees. 


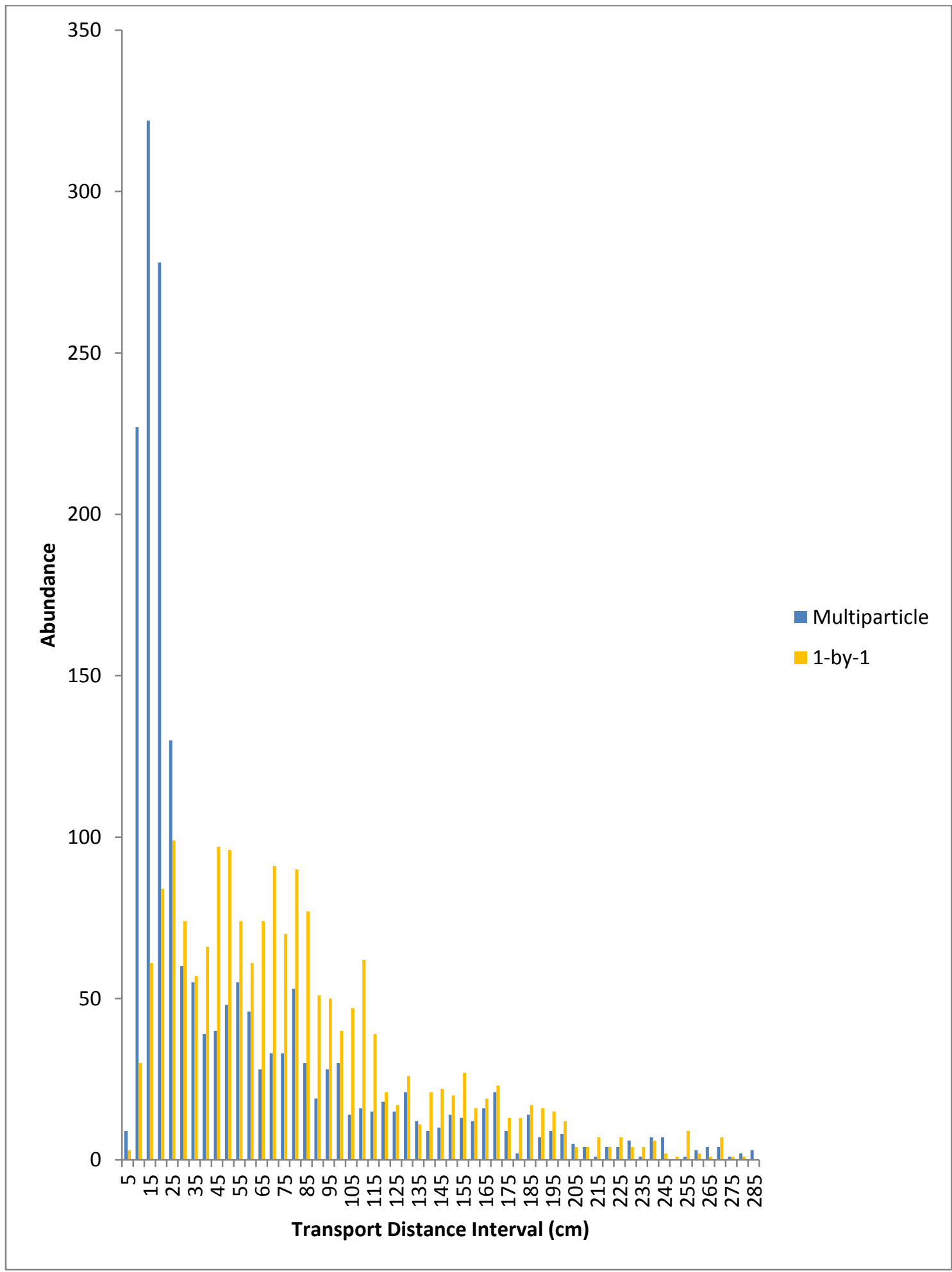

Figure 16. Transport distance histogram when $\mathrm{P}=50$ at 15 degrees. 
As previously stated, the flattening of the distribution of transport distances at higher slopes could be an indication of a shift into the inertial regime. The flattening of the distribution of transport distances was observed in the 1-by-1 experiment, but not in the multiparticle experiment. Therefore, the transition slope required to shift into the inertial regime must have increased due to sediment volume effects. In other words, the energy threshold required to transition into the inertial regime increased. Thus, if the energy of the system is increased (e.g., increased slope, increased velocity, etc.) there is a possibility that multiparticle transport could enter into the inertial regime. I doubled the initial velocity from $0.7 \mathrm{~m} / \mathrm{s}$ to $1.4 \mathrm{~m} / \mathrm{s}$ to test this hypothesis. No indication of a shift into the inertial regime was documented, but it is possible that much greater energy is required to transition into this regime (Fig. 17). These flume experiments revealed that the slope required to shift into the inertial regime is impacted by sediment volume. However, the transition slope for the multiparticle experiment was not determined because of the size limitation of the flume. A majority of the particles simply reached the end of the flume as the energy of the system (e.g., slope, velocity, etc.) was increased. 


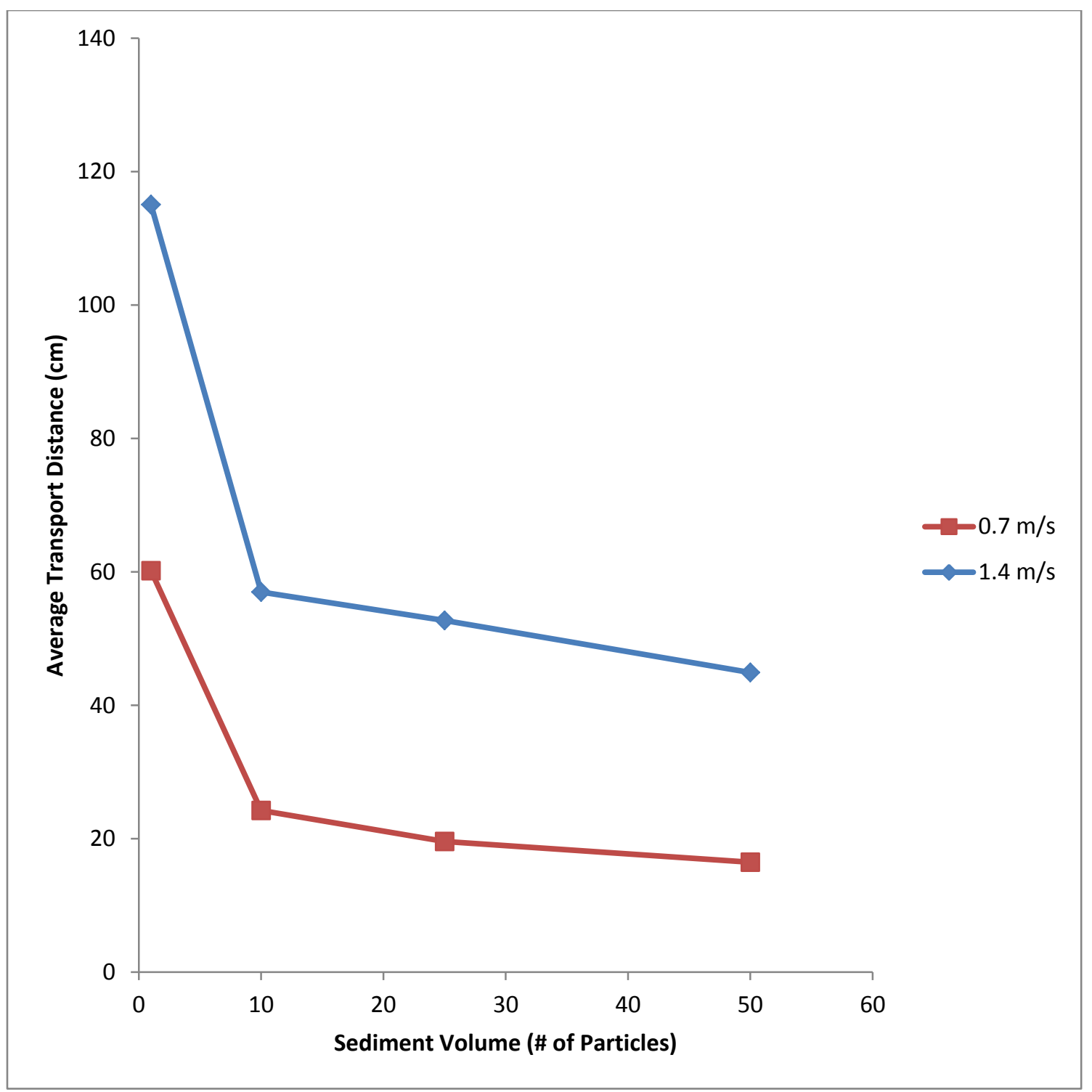

Figure 17. Transport distances vs. sediment volume at 10 degrees in which the initial velocity of $0.7 \mathrm{~m} / \mathrm{s}$ was doubled $(1.4 \mathrm{~m} / \mathrm{s})$. 


\section{Evaluation of the multiparticle transport distance equation}

Once all of the flume data were collected, Equation 3 was used to calculate the friction coefficients for all slopes in which $\mathrm{P}=1$ (single particle experiment). Based on the calculated friction coefficients, the single best-fit friction coefficient was approximated by minimizing the root mean square error (RMSE) which was 0.240 for the multiparticle experiment and 0.242 for the 1-by-1 experiment. The best-fit friction coefficient (0.22 for both the 1-by-1 and multiparticle experiments) was used in the multiparticle transport equation (Eq. 8), and the best-fit $\mathrm{K}$ and $\mathrm{n}$ values $(0.25$ and 0.35 , respectively) were approximated based on the lowest RMSE. Similarly, the best-fit K and $\mathrm{n}$ values were calculated for the 1-by-1 experiment ( 0.05 and 0.3 , respectively). Observed transport distances (d) and predicted transport distances ( $\left.\mathrm{d}^{*}\right)$ were plotted and linear regression analysis indicated a good correlation between the observed and predicted transport distances (Figs. 18-22). Therefore, transport distances predicted by the multiparticle transport equation were very similar to the observed transport distances. The best-fit equation accurately predicted transport distances at 10 degrees, but underestimated transport distances at 0 and 5 degrees. 


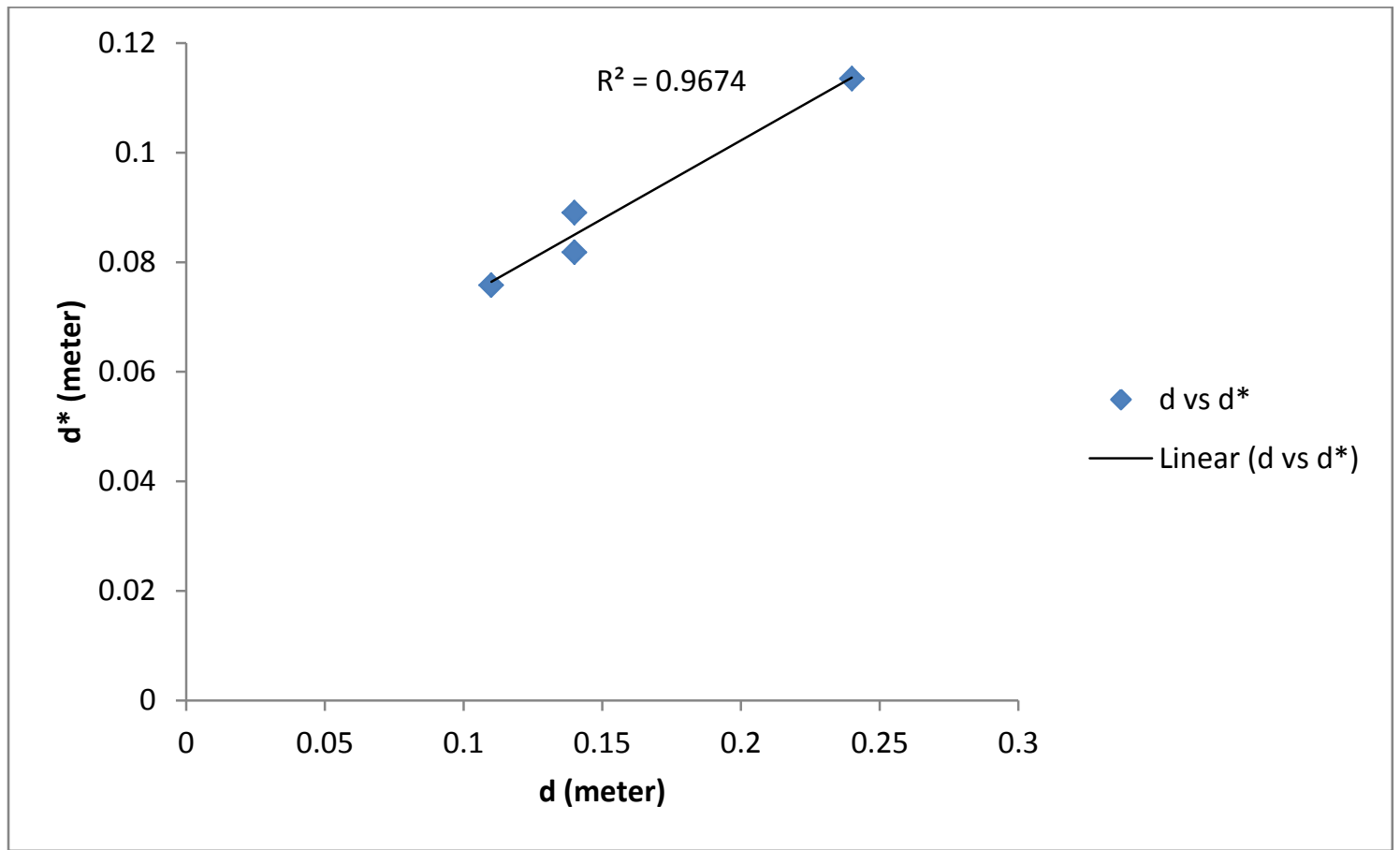

Figure 18. Multiparticle experiment: observed (d) vs. predicted (d*) transport distance at 0 degrees.

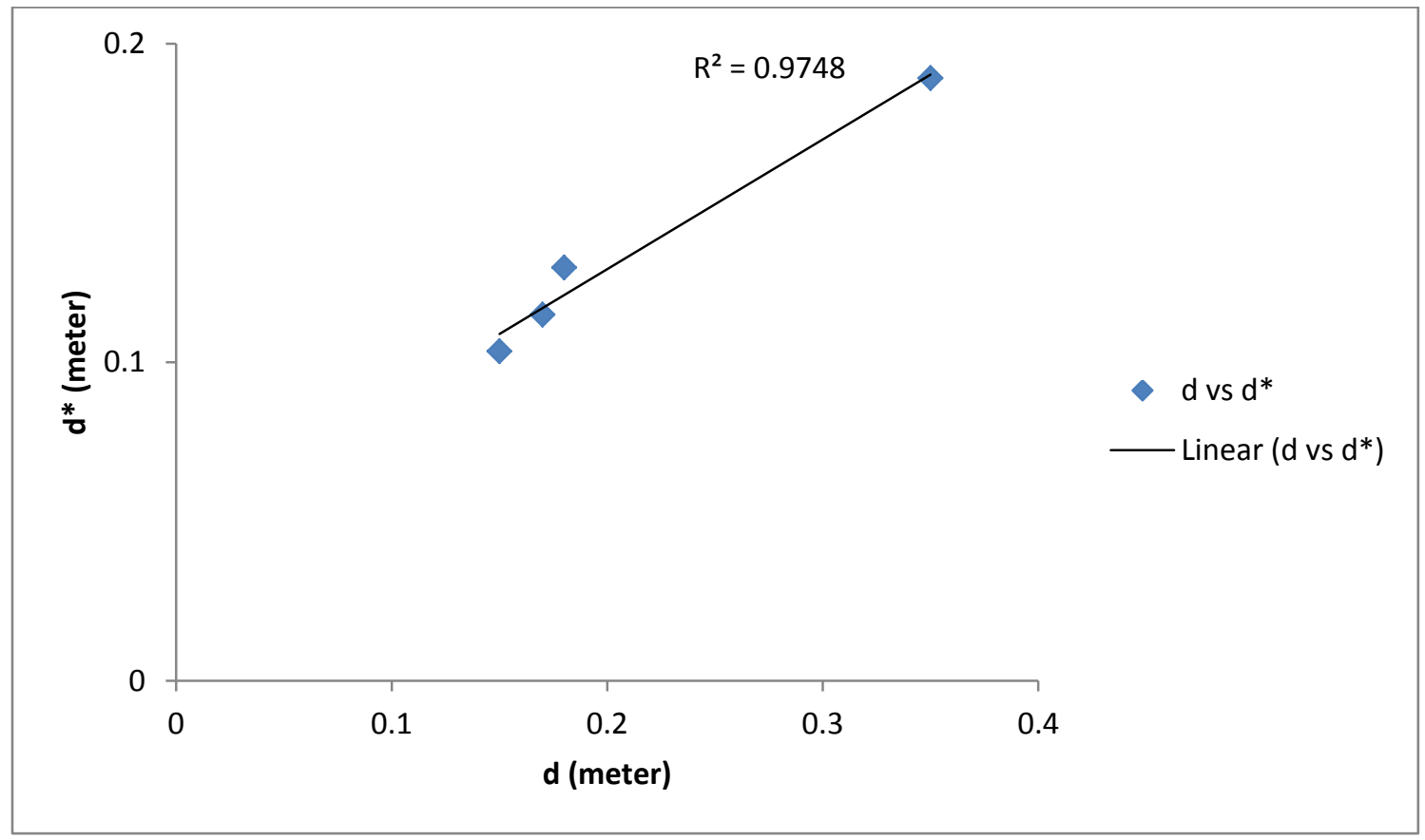

Figure 19. Multiparticle experiment: observed (d) vs. predicted (d*) transport distance at 5 degrees. 


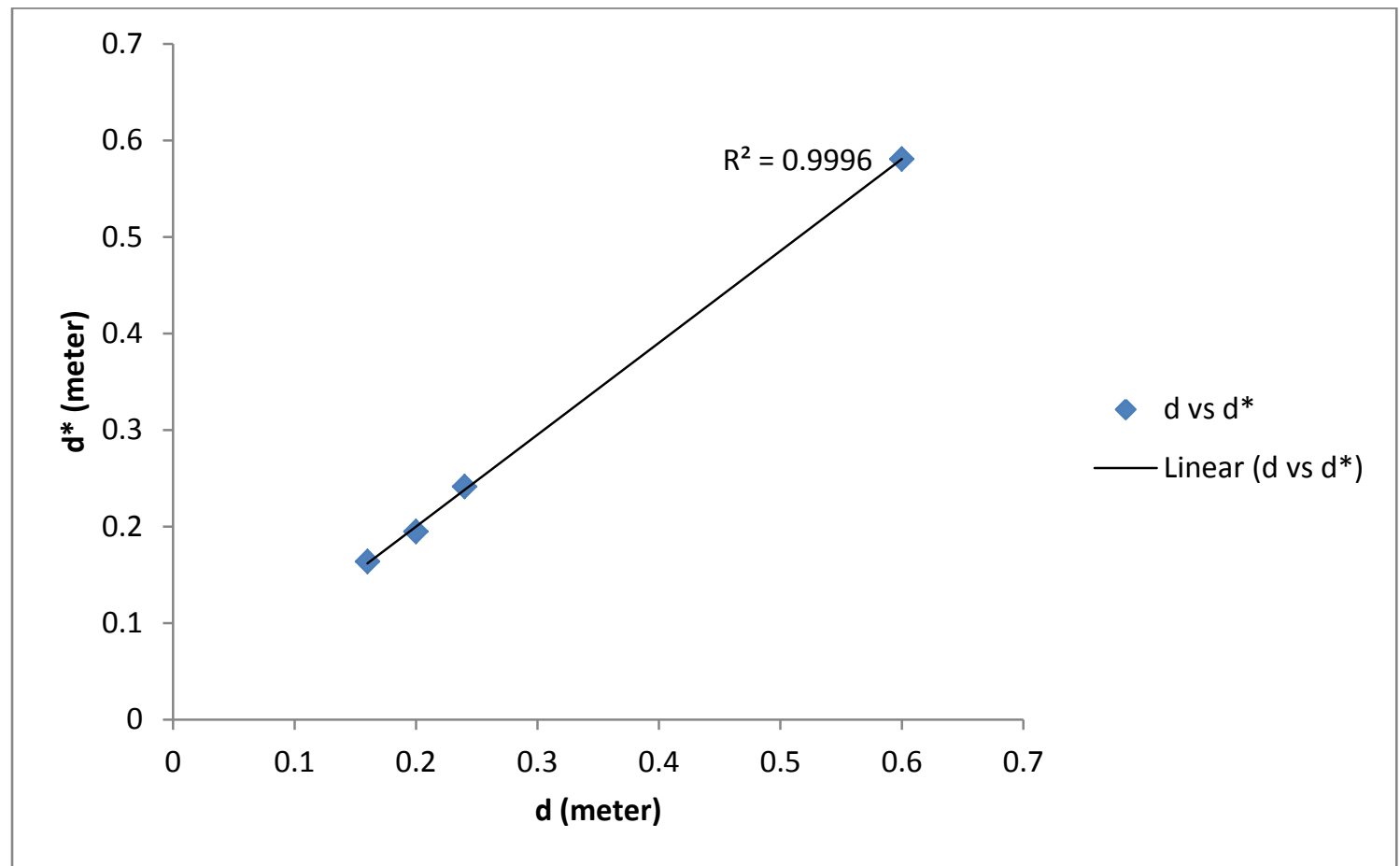

Figure 20. Multiparticle experiment: observed (d) vs. predicted $\left(\mathrm{d}^{*}\right)$ transport distance at 10 degrees.

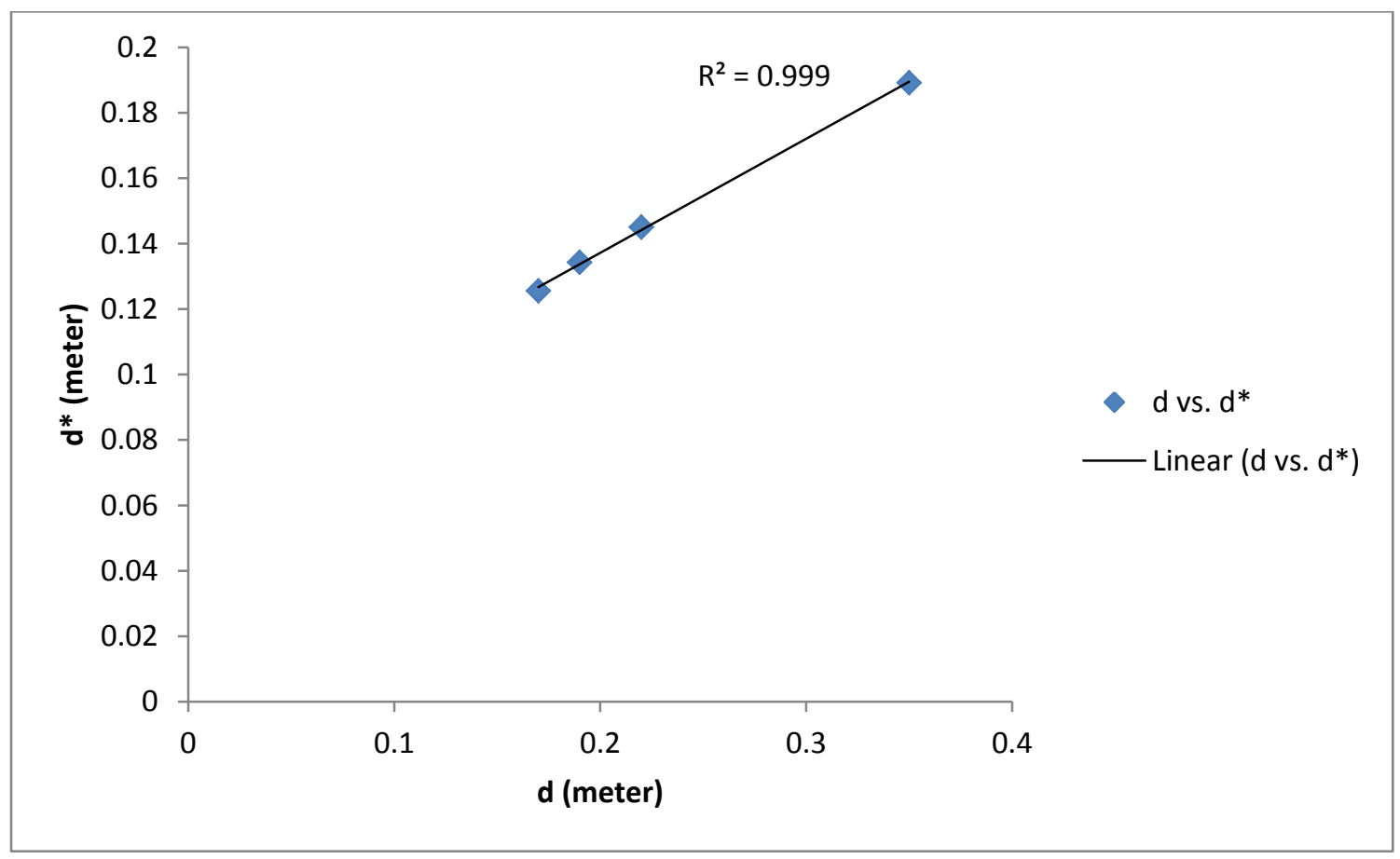

Figure 21. 1-by-1 experiment: observed (d) vs. predicted (d*) transport distance at 5 degrees. 


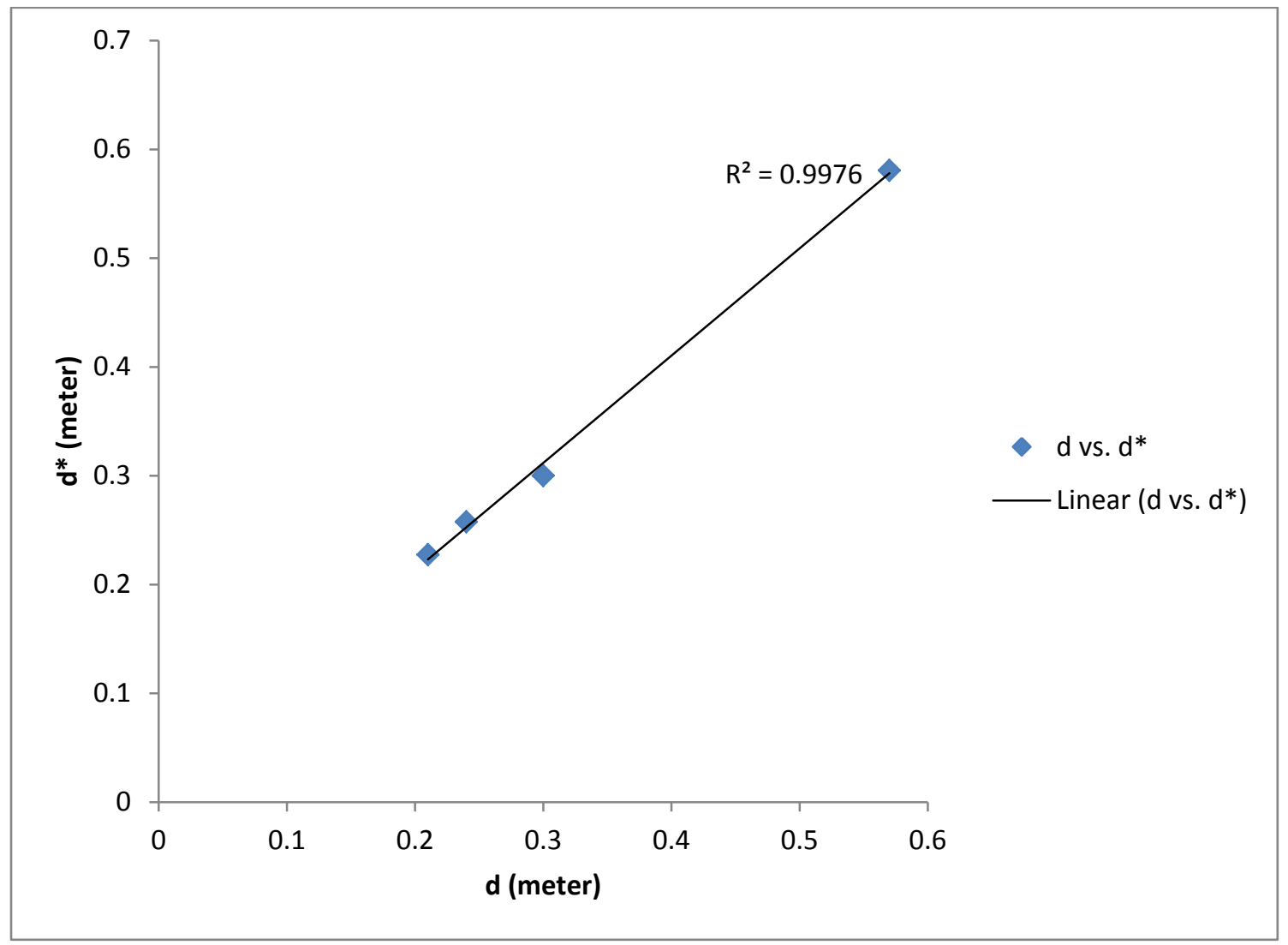

Figure 22. 1-by-1 experiment: observed (d) vs. predicted (d*) transport distance at 10 degrees. 
Transport distances were plotted against slope to visualize the effect of sediment volume (Figs. 23-24). In the multiparticle experiment, the curvature of the plot shifts as sediment volume is increased (Fig. 23). The curve is exponential when $\mathrm{P}=10$, linear when $\mathrm{P}=25$, and logarithmic when $\mathrm{P}=50$. The change in curvature supports my conclusion that a higher transition slope is required to shift into the inertial regime at greater sediment volume.

\section{The significance of multiparticle flume experiments and further studies}

This study confirmed that there is an intrinsic relationship between sediment volume, particle jamming, and transport distance. The flume experiments also revealed that increased sediment volume reduced transport distances. Furthermore, the transition slope required to shift into the inertial regime increased as a result of greater sediment volume. While these flume experiments are limited, they provide significant insight into the dynamics of sediment transport. A potential transition slope near 15 degrees in which transport entered the inertial regime was identified for the 1-by-1 experiment. However, no potential transition slope was identified in the multiparticle experiment. 


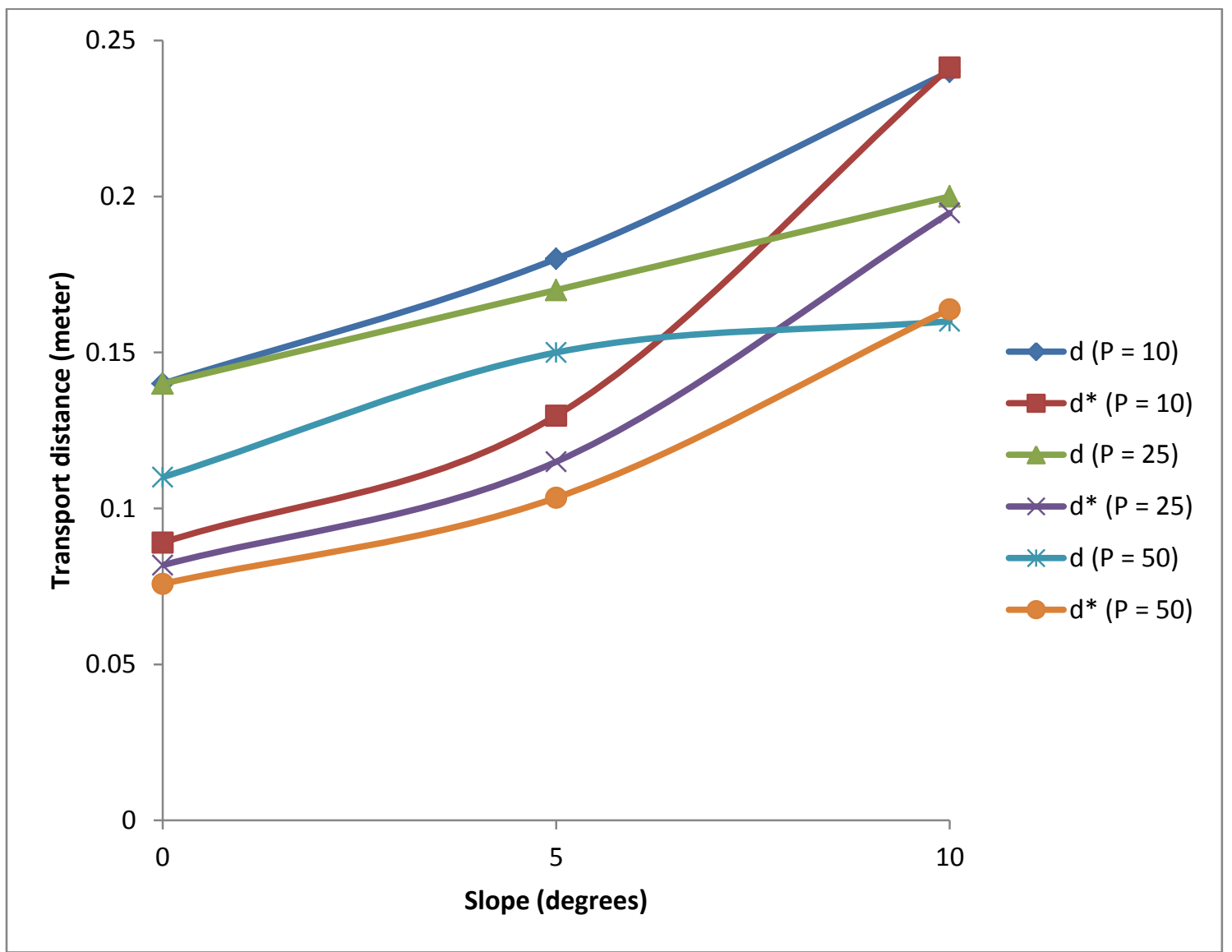

Figure 23. Transport distance vs. slope of the observed $(d)$ and predicted $\left(d^{*}\right)$ transport distance data collected in the multiparticle experiments $(\mathrm{K}=0.25, \mathrm{n}=0.35)$. 


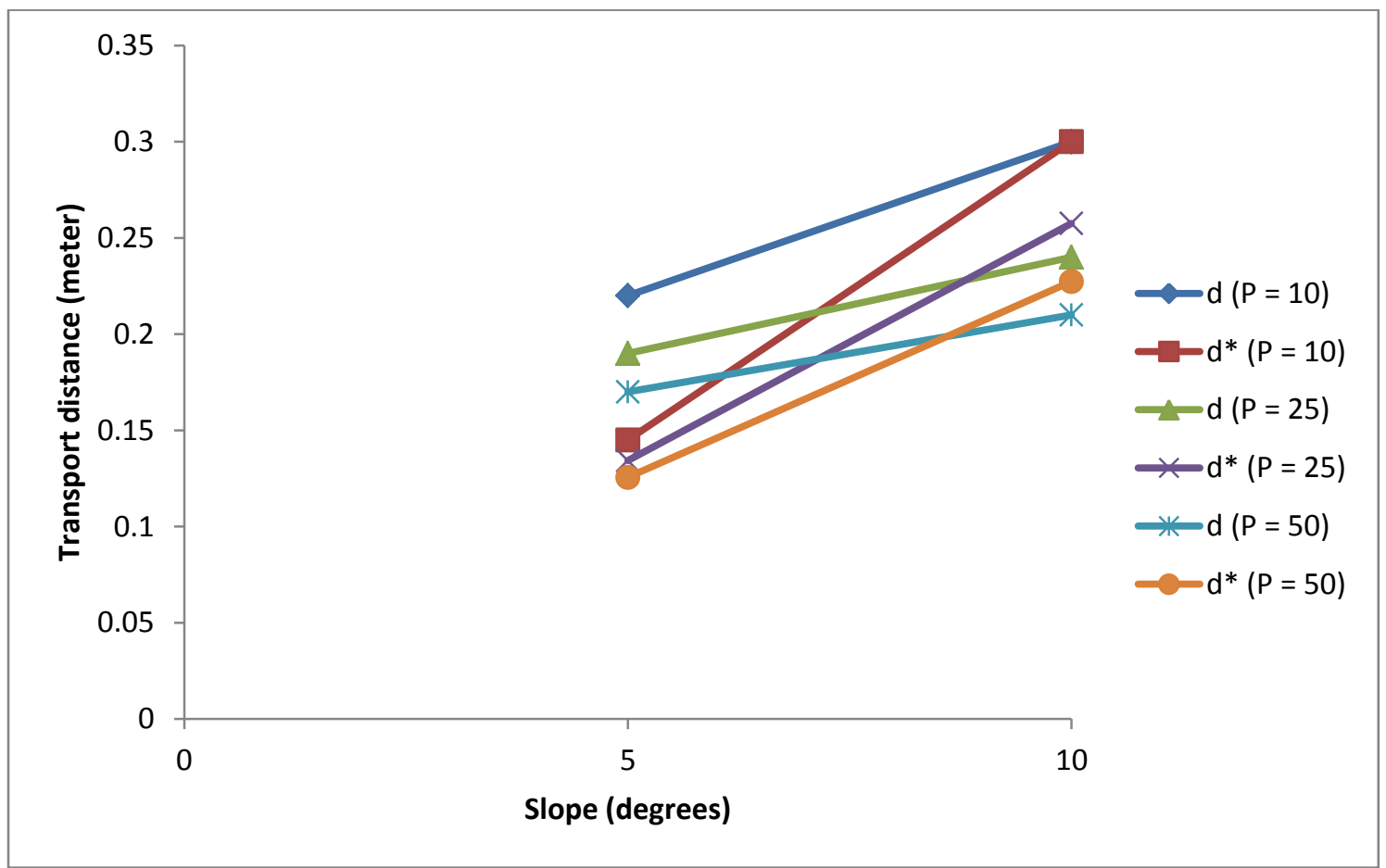

Figure 24. Transport distance vs. slope of the observed $(\mathrm{d})$ and predicted $\left(\mathrm{d}^{*}\right)$ transport distance data collected in the 1-by-1 experiments $(\mathrm{K}=0.05, \mathrm{n}=0.3)$. 


\section{CONCLUSIONS}

This flume experiment revealed a negative relationship between sediment volume and transport distance. While this is the opposite of my initial proposed hypothesis, the results are nonetheless significant because sediment volume impacts on transport distance were confirmed. The physical mechanisms that govern transport are different at gentle and steep slopes. In the flume experiments, particle jamming due to collision of mobile particles reduced transport distances. A possible transition into the inertial regime near 15 degrees was documented in the 1-by-1 experiment, but this was not observed in the multiparticle experiment. The slope required to transition into the inertial regime must have increased with greater sediment volume. Thus, a greater energy threshold must be reached in order to transition into the inertial regime. 


\section{REFERENCES CITED}

Anderson, H. W., Coleman, G. B., and Zinke, P. J., 1959, Summer slides and winter scour: Dry-wet erosion in southern California mountains: U.S. Forest Service Research Papers PSW, p. 36.

Campbell, C. S., 1990, Rapid granular flows: Annual Review of Fluid Mechanics, v. 22, p. 57-92.

Campbell, C. S., 2006, Granular material flows - An overview: Powder Technology, v. 162 , p. 208-229.

Culling, W. E. H., 1965, Theory of erosion on soil-covered slopes: Journal of Geology, v. 73 , p. 230-245.

Forterre, Y., and Pouliquen, O., 2008, Flows of dense granular media: Annual Review of Fluid Mechanics, v. 40, p. 1-24.

Foufoula-Georgiou, E., Ganti, V. and Dietrich, W. E., 2010, A nonlocal theory of sediment transport on hillslopes: Journal of Geophysical Research, v. 115, F00A16.

Furbish, D. J., and Haff, P. K., 2010, From divots to swales: Hillslope sediment transport across divers length scales: Journal of Geophysical Research, v. 115, F03001.

Gabet, E. J., 2003, Sediment transport by dry ravel: Journal of Geophysical Research, v. 108 (B1), p. 2050, doi:10.1029/2001JB001686.

Iverson, R. M., and Denlinger, R. P., 2001, Flow of variably fluidized granular masses across three-dimensional terrain: 1. Coulomb mixture theory: Journal of Geophysical Research, v. 106, p. 536-552.

Iverson, R. M., Logan, M., and Denlinger, R. P., 2004, Granular avalanches across irregular three-dimensional terrain: 2. Experimental tests: Journal of Geophysical Research, v. 109, F01015.

Kirkby, M. J., and Statham, I., 1974, Surface stone movement and scree formation: Journal of Geology, v. 83, p. 349-362.

Mendoza, M. K., and Gabet, E. J., 2012, Particle transport over rough hillslope surfaces by dry ravel: Experiments and simulations with implications for nonlocal sediment flux: Journal of Geophysical Research, v. 117, F01019, doi:10.1029/2011JF002229. 
Mollon, G., Richefeu, V., Villard, P., and Daudon, D., 2012, Numerical simulation of rock avalanches: Influence of a local dissipative contact model on the collective behavior of granular flows: Journal of Geophysical Research, v. 117, F02036, doi:10.1029/2011F002202.

Pouliquen, O., 1999, Scaling laws in granular flows down rough inclined planes: Physics of Fluids, v. 11, p. 542-548.

Pouliquen, O., and Forterre, Y., 2002, Friction law for dense granular flows: application to the motion of a mass down a rough inclined plane: Journal of Fluid Mechanics, v. 453 , p. $133-151$.

Quartier, L., Andreotti, B., Douady, S., and Daerr, A., 2000, Dynamics of a grain on a sandpile model: Physical Review E, v. 62, p. 8299-8307.

Rice, R. M., 1982, Sedimentation in the chaparral: How do you handle unusual events?: Sediment budgets and routing in forest drainage basins, edited by F. J. Swanson et al.: U.S. Forest Service Technical Paper, p. 39-49.

Roering, J. J., Kirchner, J. W., and Dietrich, W. E., 1999, Evidence for non-linear, diffusive sediment transport on hillslopes and implications for landscape morphology: Water Resources Research, v. 35 (3), p. 853-870.

Savage, S.B., and Hutter, K., 1989, The motion of a finite mass of granular material down a rough incline: Journal of Fluid Mechanics, v. 142, p. 391-430.

Statham, I., 1976, A scree slope rockfall model: Earth Surface Processes, v. 1, p. 43-62.

Tucker, G. E., and Bradley, D. N., 2010, Trouble with diffusion: reassessing hillslope erosion laws with a particle-based model: Journal of Geophysical Research, v. 115, doi:10.1029/2008JF001246. 